NUCLEAR MAGNETIC RESONANCE IMAGING OF WATER CONTENT IN THE SUBSURFACE

Prepared For:

U.S. DEPARTMENT OF ENERGY OFFICE OF ENERGY RESEARCH AGREEMENT NUMBER DE-FG07-96ER14732 


\title{
NUCLEAR MAGNETIC RESONANCE IMAGING OF WATER CONTENT IN THE SUBSURFACE
}

\author{
Prepared For: U.S. Department of Energy \\ Office of Energy Research \\ Agreement Number DE-FG07-96ER14732
}

Prepared By: Dr. Jan M.H. Hendrickx, Dr. T. (Mike) Yao, and Anne Kearns New Mexico Institute of Mining and Technology Department of Earth and Environmental Science

801 LeRoy Place

Socorro, New Mexico

Tel: $505-835-5892$

Fax: 505-835-6436

email: hendrick@nmt.edu

In Association With: Dr. Pieter Hoekstra, Richard J. Blohm, Mark W. Blohm,

Dr. Peter B. Weichman and Dr. Eugene M. Lavely

Blackhawk Geometries, Inc.

301 Commercial Road, Suite B

Golden, Colorado 80401

Tel: $303-278-8700$

Fax: 303-278-0789

email: mark@blackhawkgeo.com

January 21, 1999 


\section{Contents}

1 INTRODUCTION 4

2 BACKGROUND INFORMATION 6

2.1 Motivation for Imaging Subsurface Water Content . . . . . . . . . . . . 6

2.2 Nuclear Magnetic Resonance Imaging of Water Content . . . . . . . . . . . 7

3 PRINCIPLES OF SURFACE NUCLEAR MAGNETIC RESONANCE IMAGING

3.1 General Principles . . . . . . . . . . . . . . . . . . . . . 9

3.2 Fundamentals of Surface NMR Imaging of Water Content Distribution . . . . . . . 9

3.3 Signal to Noise characteristics . . . . . . . . . . . . . . . . . 11

3.4 Relaxation Times . . . . . . . . . . . . . . . . . . . . . 12

4 THE NUMIS INSTRUMENT 15

5 DATA ACQUISITION AND PROCESSING 16

5.1 Determination of the Larmor Frequency . . . . . . . . . . . . . 16

5.2 Instrument Calibration. . . . . . . . . . . . . . . . . . . 16

5.3 Selection of Acquisition Parameters . . . . . . . . . . . . . 16

5.4 Acquisition Process, Signal Stacking, and Recording .............. . 16

5.5 Data Processing and Interpretation . . . . . . . . . . . . . . . . . . . 17

6 DESCRIPTION OF MEASUREMENT SITES

6.1 Colorado. . . . . . . . . . . . . . . . . . 18

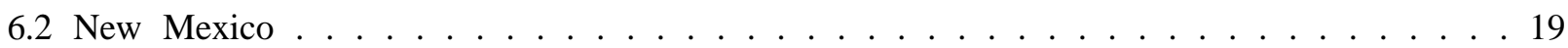

7 RESULTS AND DISCUSSION 22

7.1 Colorado Sites . . . . . . . . . . . . . . . . . . 22

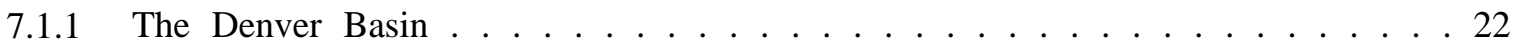

7.2 New Mexico Sites . . . . . . . . . . . . . . . . . . 24

7.2.1 The Rio Grande Valley . . . . . . . . . . . . . . . . . . 24

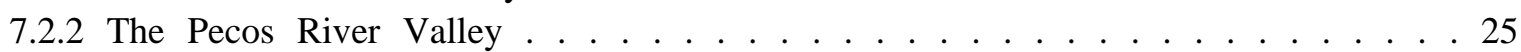

7.2.3 The Tularosa Basin . . . . . . . . . . . . . . . . 26

7.2 .4 The San Juan Basin . . . . . . . . . . . . . . . . . 27

8 CONCLUSIONS $\quad 28$

9 REFERENCES $\quad 30$

A GEOLOGICAL DETAILS

A.1 The San Juan Basin (Sites 17, 18, 19, 20) . . . . . . . . . . . . . . . . 33

A.2 The Rio Grande Valley (Sites 1, 2, 3, 4, 5, 6, and 7) . . . . . . . . . . . 33

A.2.1 Isleta Lake Site $($ Site 7$) \ldots \ldots \ldots \ldots \ldots \ldots \ldots$

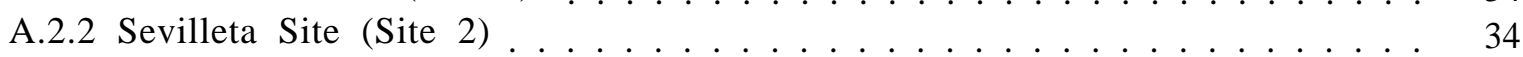

A.2.3 Rio Salado Site $($ Site 1) . . . . . . . . . . . . . . . . . . . . 34

A.2.4 Bosque de1 Apache Site (Site 3) . . . . . . . . . . . . . . . . 35

A.3 The Tularosa Basin (Sites 13, 14, 15, 16) . . . . . . . . . . . . . 35 
A.4 White Sands National Monument . . . . . . . . . . . . . . . . 35

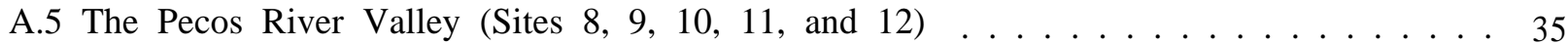

A.5.1 Santa Rosa Lake Site $($ Site 8$) \ldots \ldots \ldots \ldots \ldots \ldots \ldots \ldots$

A.5.2 Lea Lake Site $($ Site 9$) \ldots \ldots \ldots \ldots \ldots \ldots$

A.5.3 Dexter Agricultural Field Site (Site 11) . . . . . . . . . . . . 37

A.5.4 Lake Arthur Agricultural Field Site (Site 12) . . . . . . . . . . . . 38

A.5.5 New Mexico State University Experimental Station Site . . . . . . . . 38

B THEORETICAL PREPRINT 39 


\section{INTRODUCTION}

This report contains the experimental, theoretical and numerical studies performed under Department of Energy (DOE) Agreement Number DE-FG07-96ER14732 entitled "Surface Nuclear Magnetic Resonance for Imaging Subsurface Water."

DOE and Department of Defense (DOD) complexes and test ranges are situated in widely varying climatic conditions from the desert southwest to the humid east. The mission of the Office of Environmental Restoration and Waste Management (EM) is to clean up the inventory of inactive DOE sites and facilities, and the goal of the EM Office of Technology Development (OTD) is to deliver technologies to make environmental restoration more efficient and cost effective. In the western United States, where a number of DOE facilities are located, the water table can occur several hundred feet below the surface. The zone between surface and water table is called the vadose zone or unsaturated zone. A characteristic of that zone is that mobility of water and contaminants is greatly reduced compared to rate of movement in the saturated zone. A thick vadose zone lowers the risk and, at least, increases the time before contaminants enter drinking water supplies. The assessment of risk is often performed by modeling of ground water flow and contaminant migration by analytical methods or unsaturated flow models (e.g. Hendrickx et al 1991). Necessary inputs for these models are the hydraulic properties of the different geological formations (e.g. Hendrickx 1990) and the water content distribution in the vadose zone (Freeze and Cherry 1979). Accurate risk assessments for ground water contamination cannot be conducted without actual measurements of the water content distribution in the vadose zone. To date, very few techniques have been developed to provide such information at an acceptable speed and cost. Because soil water contents exhibit a large spatial and temporal variability, the costs of conventional measurement techniques, such as gravimetric sampling, gypsum blocks, and neutron probes, are high. Only non-intrusive tests with a cost factor much lower than that of an intrusive test will offer acceptable alternatives. Therefore, a definite need exists for a non-intrusive water content measurement method.

The surface nuclear magnetic resonance (NMR) technique applied to imaging of ground water was first developed by Russian scientists from the Institute of Chemical and Combustion in Novosibirsk, Russia. Over the last two decades they have published a series of papers and reports describing the theory of the method, along with experimental measurements from the surface to a depth of about $100 \mathrm{~m}$. Preliminary evaluation of the concepts and results merited further investigations, particularly because of the critical technical need for cost-effective water content measurements in environmental restoration.

The work under this contract proceeded along two parallel directions:

1 Experimental NMR measurements at sites in Colorado and New Mexico with control on geologic and hydrogeologic conditions. The equipment used for the measurements was the NUMIS equipment manufactured by IRIS Instruments of fiance. This equipment follows the design of the original equipment of the Russian scientists.

1 Generalization of the NMR theory to correctly model the NMR response from conductive ground, along with numerical implementation of the corrected theory to assess significance of the theoretical corrections and to understand properties of the inverse problem.

Concurrent with our investigations of surface NMR imaging of water content in the subsurface, active development was ongoing in oil exploration and oil service companies on NMR logging in boreholes, and by laboratory measurements on samples to better understand the NMR response 
of water in soils and rocks. NMR logging is rapidly becoming an important tool in reservoir engineering because in principle information about permeability can be derived.

The results from the experimental measurements performed under this contract show that the ability to record reliable data and infer water content distributions from the data is site specific. Proper inference of water content requires knowledge of the geolectric section, which must be obtained from a separate measurement and is often known only with limited accuracy. Present equipment limitations sometimes preclude obtaining reliable measurements of water content in several soil and rock types, such as soils and rocks with magnetite (ferromagnetic mineral) and fine grained soils. At sites where reliable measurements were recorded, the tool shows the power of the technology in that constraints on both water content and permeability may be obtained. The published literature describes case histories at highly selective sites and does not adequately address several of the technique's limitations. Under this contract, experimental measurements were made at sites with widely varying hydrogeologic conditions, so that the range of applications and limitations could be evaluated.

Under this DOE contract, major advances were made in development of the theory and the computational algorithms and programs to derive water content from surface NMR measurements. The theoretical work and numerical simulations are described in a preprint to be submitted to Physical Review and is attached to this report as Appendix B. 


\section{BACKGROUND INFORMATION}

\subsection{Motivation for Imaging Subsurface Water Content}

Water is the transport vehicle for migration of hazardous substances and thus a critical factor in restoration alternatives and costs. Information on the location, depth, and subsurface distribution of water and its dissolved waste materials is needed for proper and safe management of environmental restoration projects and waste storage facilities. To date, very few techniques have been developed to provide such information at an acceptable speed and cost. Most of the present techniques are intrusive. Geophysical techniques are based on establishing a correlation between a physical property and water content (e.g. electrical resistivity) and require calibration by intrusive tests. Because soil water contents exhibit a large spatial and temporal variability, the costs of conventional measurement techniques such as gravimetric (weighing and drying) sampling, gypsum blocks, and neutron probes are high. Therefore, a definite need exists for a non-intrusive water content measurement method.

As stated in the Introduction, necessary inputs for the modeling of groundwater flow are the hydraulic properties of the different geological formations and the water content distribution in the vadose zone. At present, a consensus exists among vadose zone hydrologists that indirect methods for determination of the hydraulic properties of geologic formations based on readily available information often yield estimates with au accuracy that is quite acceptable for many applications (Van Genuchten et al. 1992). However, accurate risk assessment for ground water contamination cannot be conducted without actual measurements of the water content distribution in the vadose zone.

A simple case representative of many contaminated sites with deep vadose zones in dry and humid areas of the U.S. can illustrate this. Water contents in deep vadose zones in the Southwest may vary between 1 and 10 volume percent. Measurements in New Mexican desert soils show that at depths below 2 to 3 meters this water content often does not change with time. Therefore, consider a vadose zone with a thickness of $30 \mathrm{~m}$ (100 feet) and a volumetric water content of $5 \%$. This vadose zone contains a total of $1.5 \mathrm{~m}^{3}$ water per unit area of $1 \mathrm{~m} 2$. A constant water content with time does not preclude downward flow as is sometimes erroneously assumed. The constant water content with time is consistent with a steady downward movement of water and dissolved contaminants. Water balance calculations using meteorological data can be used to assess mean downward groundwater percolation rate in New Mexico and is between $3 \mathrm{~mm}$ and $37 \mathrm{~mm}$ (of saturated water) per year (Stephens 1995). The traveltime for groundwater contaminants from surface to ground water level varies between $1.5 / 0.003=500$ years and $1.5 / 0.03=50$ years. If this vadose zone would have a volumetric water content of 2.5 (instead of 5) volume percent, the travel times estimates decrease to approximately 250 and 50 years. This example shows the dramatic effect of a small change in water content on contaminant travel times and risk for groundwater contamination. Accurate nonintrusive measurements of vadose zone water content combined with deep percolation estimates allow risk assessment without expensive drilling, and complicated modeling studies.

The assumption of steady state in the above case study has been corroborated for arid and semi-arid areas by Hendrickx et al. (1991). At sites in more humid areas or with gravel vadose zones, water movement will show a more transient character. Under these conditions, fate and transport models have to be used to evaluate the travel times of contaminants. Important input parameters for these models are the hydraulic properties of the vadose zone and its initial water content. Modeling studies revealed that their results are sensitive to the hydraulic parameters (see, e.g., Hendrickx et al. 1991), so that all models need to be calibrated comparing measured and simulated water contents. Such calibrations can only be accomplished when reliable water content 
measurements are available over the entire vadose zone depth.

To measure water content non-intrusively by geophysical measurements presently requires a correlation between a physical property such as electrical conductivity, density, compressional wave velocity, and water content. For example, the relation between electrical conductivity and water content was used by Sheets and Hendrickx (1995) to monitor soil water content changes in desert soils with the electromagnetic induction (EM) method. They showed that for shallow subsoils to depths of approximately 20 feet, this method has a great potential to quickly determine and monitor water content over large areas. The ease of application of the EM method and its low cost make it an appealing method for monitoring near surface ( 0 to 20 feet) water content over time and space.

Although several physical properties relate to water content, no method is sufficiently unique to allow water content measurements solely by a geophysical method. For example, the EM work by Sheets and Hendricks (1995) and Kachanoski et al. (1988) indicates that calibration is needed. At the present time, there is no non-invasive method to make accurate measurements of water content distributions in deep vadose zones uniquely related to water.

\subsection{Nuclear Magnetic Resonance Imaging of Water Content}

Theoretical work and laboratory experiments (Andreyev and Martens 1960; Prebble and Currie 1970; Semenov 1987; Shirov et al. 1991) have proven that the parameters associated with the gyromagnetic moment of protons in water are directly and uniquely related to liquid water content. These parameters are measured by nuclear magnetic resonance. Paetzold et al. (1987) conclude from their laboratory experiments that the NMR signal is a linear function of volumetric water content and is not affected by clay mineralogy, soil organic matter, or texture within the ranges studied. They concluded that the NMR signal is indeed uniquely related to liquid water in soils and other rocks.

The application of NMR for detection of underground water was first proposed by Varian (1962). The successful realization of this technique in field tests was not implemented until 1978 with prototype equipment developed in the Institute of Chemical Kinetics and Combustion at Novosibirsk (Russia) by Semenov et al. (1989) and Trushkin et al. (1994). Development continued and resulted in an instrument called the "Hydroscope" claimed capable of non-invasive groundwater detection and measurement of depth, thickness, and water content of aquifers. A recent field test in Australia was reported by Shirov et al. (1991). They concluded that the Hydroscope with its NMR technology is applicable to Australian conditions and can be used to reliably measure the volume of underground water, but needs improvement to measure the depth and porosity of the water containing strata. Another pertinent study has been undertaken Goldman et al. (1994) and Gev et al. (1996) in Israel. These investigators combined two proven methods: (i) the NMR method that is able to detect directly the presence of fresh water in the subsurface, and (ii) the Time Domain Electromagnetic (TDEM) method that measures the geoelectric section from which often soil types and concentration of dissolved solids can be inferred. Their study showed that the integrated application of these two methods is promising for non-intrusive delineation of ground water bearing aquifers and the simultaneous evaluation of water quality. The importance of taking into account the geoelectric section is also discussed by Shushakov (1996).

The studies in Israel and in Australia confirm the good results obtained previously in Russia. A demonstration of the Russian equipment, the Hydroscope, in the United States under sponsorship of USGS and EPA (Lieblich et al. 1994) confirmed again that: (i) the theoretical concepts of the NMR technique are sound; (ii) the equipment exists and is operational; and (iii) that likely the equipment and analysis process can be improved with western computational and electronic technology. The 
design of the Russian "Hydroscope" was basically adapted in the NUMIS equipment built by IRIS Instruments of France. Limitations of the method have not received the same attention as the successes. Goldman et al. (1994) addressed the interference by power lines and the need to select sites at substantial distances from power lines. The influence of the many parameters of a soil-water system, such as surface-to-volume ratio, presence of ferromagnetic minerals and paramagnetic ions, and the subsurface geoelectric section, on water content measurements is not discussed much in the existing literature. The published results leave the impression that surface NMR imaging of water content is a technology ripe for exploitation in practice. However, the experimental measurements performed under this contract over a wide range of geologic settings reveal that the successful application is highly site specific, and that a number improvements in the data analysis and the instrument technology must be made before it becomes a routine tool. 


\section{PRINCIPLES OF SURFACE NUCLEAR MAGNETIC RESO- NANCE IMAGING}

\subsection{General Principles}

The principles and theory of surface NMR imaging are discussed in this report at two levels. Fit, the physics of the process is conceptually explained with extensive use of graphics. Second, the mathematical formulation of the theory (both forward and inverse) has been prepared for publication (reproduced as Appendix B of this report). The objective of the conceptual explanation is to allow an understanding of the principles of the surface NMR method, the range of application, and the problems encountered with theory and experiments without having to resort to relatively involved mathematical formulations. The mathematical formulations, however, are required for development of the forward and inverse computations of water content distribution in the subsurface from surface measurements.

The theoretical and computational aspects of surface NMR imaging developed under this contract, and reproduced in Appendix B, contain several fundamentally new developments:

- The theoretical development of an imaging equation accounting properly for the geolectric section on the NMR response. The diffusion time of electric currents in the ground strongly influences the measured response in ways never previously accounted for properly. A particular special case where the resistivity is horizontally stratified with depth is treated explicitly. In most other electromagnetic geophysical applications, the electromagnetic field needs to be computed on or above the surface of the ground and computation of the electromagnetic field in the subsurface adds complexity.

- A computationally efficient algorithm for computing the required subsurface magnetic fields for input into the imaging equation.

- A computationally efficient approach to inversion of the data in terms of water content using the new imaging equation. The new inversion scheme exhibits significant shortcomings in the algorithm used by the NUMIS instrument. In ongoing work the new algorithm will be used to reananalyze the field data described later in this report.

\subsection{Fundamentals of Surface NMR Imaging of Water Content Distribution}

The geophysical surface NMR method has similarities and differences with the NMR measurements commonly made in controlled laboratory experiments and in the medical field. In both experimental set-ups, the fact that a hydrogen nucleus (proton) has a spin is exploited. The angular momentum and the magnetic moment of the spin are coaxial (Figure 3-1). In both the geophysical field environment and in a controlled laboratory experiment use is made of a static magnetic field, and a dynamic ac magnetic field whose component perpendicular to the static field is used to manipulate the spins. Figure 3-2 compares a typical controlled laboratory set-up and the geophysical field set-up. One of the differences between the two techniques is the low intensity of the Earth's magnetic field compared to the fields that can be applied in laboratory experiments. In the laboratory environment, samples can be placed in strong magnetic fields. Another difference is the control over the geometry of the experiment. In laboratory measurements on small samples the geometry can be controlled, and the spatial resolution of the signal can be focused precisely on the targets of interest. In the geophysical experiment, the geometry is restricted to the Earth's surface and 
control over geometry leaves much to be desired. Most of the data analysis then focuses on deconvolving the influences of geometry from the signal of interest. The crucial information is averaged with a complicated weighting function whose input parameters must be inferred from independent measurements of the geoelectric section.

When an external magnetic field is applied to material containing water molecules, the material will be magnetized, because more proton moments will preferentially align with the external magnetic field. The net nuclear magnetization, $M$, is given by,

$$
\mathrm{M}=k N \mathrm{~B}_{0}
$$

where $\mathrm{B}_{\mathrm{O}}$ is the external magnetic field (the earth's field in geophysical applications), $k$ is a constant (the nuclear magnetic susceptibility) inversely proportional to temperature, and $N$ is the number of protons per unit volume (equal to twice the number density of water molecules). Equation (1) expresses the crucial proportionality between net magnetization and water content. Thus, if the nuclear magnetization could be measured directly, it would be found proportional to the number of protons and water molecules per unit volume. The generation of a net magnetization of a substance in response to an external magnetic field is called paramagnetism. In the present case, the smallness of $\boldsymbol{k}$ makes it a very small effect: in the earth's field typically only one in $10^{10}$ protons will be aligned with the external field in the temperature range of interest in geophysical measurements. The net magnetization is in fact far too small to be measured directly (i.e., by a magnetometer).

The strength and orientation of the earth's field changes with latitude and is about 0.5 Gauss on average. The orientation of the Earth's magnetic field is near horizontal at the equator and near vertical at the poles (Figure 3-3). It is then the small net magnetization of the proton nuclear spins caused by this field that is the essentially unique signature of subsurface water. This alignment is a result of the interaction between the static field and the magnetic moment of the protons. The static field induces a torque on the nuclear spins which causes them to precess about it a characteristic Larmor frequency

$$
\omega_{L}=\gamma B_{0}
$$

where $\gamma$ is the gyromagnetic ratio, which has a characteristic value of about $4260 \mathrm{~Hz} / \mathrm{G}$ for protons in liquid water. In the earth's field, the Larmor frequency has a value between 2 and $2.5 \mathrm{kHz}$.

Although the net magnetization caused by the static field is not measurable by static means, a dynamic measurement can be made. The ac field $\mathbf{B}_{1}$, generated by an ac current at the Larmor frequency in a transmitter loop laid out on the ground (see Figure 3-2), causes the spins to steadily tip away from the direction of the static field. The final tip angle is

$$
\theta=\gamma B_{1}^{\perp} \tau_{p}=G_{0} Q
$$

where $\tau_{p}$ is the duration of the pulse, $B_{1}^{\perp}$ is the magnitude of the component of $\mathbf{B}_{1}$ that is perpendicular to $\mathbf{B}_{0}$. The pulse moment is defined by $Q=I_{T} \tau_{p}$, where $I_{T}$ is the amplitude of the transmitter loop current during the pulse. Since $\mathbf{B}_{\mathbf{1}}$ is directly proportional to $I_{T}$, the tipping angle $\theta$ actually then depends only on $Q$, with a proportionality constant $G_{0}$ determined by the geometry of the loop and the geoelectic section of the subsurface. In what follows, it is only the pulse moment of a particular measurement that will then be quoted. After the ac field is terminated, the tipped spins then continue to precess about $\boldsymbol{B}_{\boldsymbol{v}}$. This precession now generates an ac magnetic field at frequency $\omega_{L}$ which in turn generates a measurable voltage in the receiver loop. The field $B_{1}^{\perp}$ scales linearly with the amplitude of the current in the transmitter loop, but is nonuniform in space. Its magnitude depends on the position of the spin relative to the transmitter loop. Figure 3-4 shows color contours of the intensity of $B_{1}^{\frac{1}{1}}$ in a two-dimensional plane through the center of the 
loop. The contours show that the field intensity falls off rapidly outside the transmitter loop. The intensity of the field is highest under the transmitter loop wires. The variation in field with depth is mainly due to geometry of the loop. On these $100 \mathrm{~m}$ scales, attenuation of the field due to finite ground conductivity generally becomes important at resistivities less than $10 \Omega$-m. Attenuation is governed by the skin depth of the electromagnetic radiation at the Larmor frequency. The skin depth at $2 \mathrm{kHz}$ is shown in Figure 3-5 for a range of ground resistivities. Generally, at resistivities greater than about $30 \Omega-m$, the skin depth will exceed the effective exploration depth of the NMR measurement. The mathematical protocols for correcting for the influence of the geoelectric section are discussed in detail in Appendix B.

To summarize, the effect of applying an alternating magnetic field (at the Larmor frequency) is to cause the nuclear spins to tip away from the static field $\mathbf{B}_{\mathbf{0}}$. The tip angle away from the Earth's magnetic field is controlled by the product of the magnitude of the component of the local ac magnetic field perpendicular to $\mathbf{B}_{0}$, and the length of time of the applied pulse [equation (3)]. Since the ac field varies with depth, the tip angle of the protons is also a function of depth. After termination of the ac pulse, the spins eventually return to equilibrium along Earth's magnetic field (Figure 3-1). In the geophysical measurement, the transmitter coil at the surface is also used as the receiver coil which picks up the induced signal from the precessing protons. The induced signal from any given location within the earth is maximized if the protons are tipped $90^{\circ}$. For a transmitting coil at the surface, this 90 degree tip angle will occur at different depths and locations for different pulse moments. Figure 3-6a and $\mathrm{b}$ show the tip angle as a function of depth for two pulse moments, 1500 amperes-milliseconds (A-ms) and $6000 \mathrm{~A}-\mathrm{ms}$. The tip angle near $90^{\circ}$ is shown in green. Figure 3-6 shows that close to the wire the tip angle can be very large and in general has values of several multiples of $360^{\circ}$. This means that the spins rotate completely around one or more times during the applied pulse. In these areas the signal will actually destructively interfere, and the overall sensitivity to water there is actually smaller than at greater depths. At larger pulse moments (6000 A-ms), the $90^{\circ}$ tip angle is more uniformly distributed at depths on the order of the radius of the transmitter loop. It is the fact that the pulse moment changes the distribution of tip angles with depth that gives rise to the required depth resolution that allows one to derive the water content distribution from surface measurements. Maximum pulse moments for the NUMIS equipment for a circular loop of $100 \mathrm{~m}$ diameter is about 9000 A-ms. Due to the rapid drop-off in the transitted field amplitude with depths greater than the size of the transmitter loop, the maximum effective exploration depth is also about $100 \mathrm{~m}$.

\subsection{Signal to Noise characteristics}

The reliability and accuracy of measuring the signal of the precessing protons is determined by signal strength, ambient electromagnetic noise, and the processing software used to resolve signal from noise. The amplitude of the voltage induced in the receiver coil at the surface is small, varying from $10 \mathrm{nV}$ to a maximum of $600 \mathrm{nV}$. It is evident from the discussion in this section that signal amplitude is proportional to the applied static (Earth's field) and to the receiver loop geometry. It is only through adjustments of the latter that signal enhancement may be optimized.

The low signal amplitude is a major disadvantage of surface NMR measurements since the signal must often be measured in the presence of large ambient noise sources. Power lines are a major source of noise, and it is instructive to compute the voltages induced by power line noise and compare them to maximum signal amplitude. Power lines commonly consist of either two wires $180^{\circ}$ out of phase or three wires $120^{\circ}$ degrees out of phase carrying currents whose sum is zero. The magnetic field amplitude, $B_{P}$, due to power lines scales as

$$
B_{p} \sim \mu_{0} I d / 2 \pi r^{2},
$$


where $\mu_{0}$ is the permeability of free space, $I$ is the current amplitude, $d$ is the separation between the wires, and $r$ is the distance from the wires to the center of the receiver loop. The flux, $\Phi_{p}$, of $\boldsymbol{B}_{\boldsymbol{P}}$ through a circular receiver loop with diameter, $l$, will be,

$$
\Phi_{p} \sim \mu_{0} I d l^{2} / 8 r^{2}
$$

and the corresponding voltage induced in the loop will be

$$
V_{p} \sim \mu_{0} \omega_{p} I d l^{2} / 8 r^{2}
$$

where $\omega_{p}$ is the power line frequency (e.g., $60 \mathrm{~Hz}$ ). For $I=100 \mathrm{~A}$, and $r=1 \mathrm{~km}$, the induced voltage in a circular loop is on the order of a millivolt, four or five orders of magnitude larger that the expected groundwater signal. Noise can be significantly reduced by making measurements with a figure eight loop. For such a loop the flux will scale with the difference of the field across the size of the loop. This yields a net flux

$$
\Phi_{8} \sim \mu_{0} I d l^{3} / r^{3}
$$

and a corresponding induced voltage,

$$
V_{8} \sim \mu_{0} \omega_{p} I d l^{3} / 8 r^{3}
$$

This shows that the noise induced in a figure eight loop is expected to be a factor of order $1 / r$ smaller than the noise in a circular loop. For $1=100 \mathrm{~m}$ and $r=1 \mathrm{~km}$, noise reduction may be by a factor of ten or more. The fact that the frequency of power line noise is $60 \mathrm{~Hz}$, while the signal from the precessing nuclear spins is about $2 \mathrm{kHz}$, shows also that significant noise reduction is achievable by filtering. However this is limited by the fact that the frequency window of the receiver generally needs to be on the order of 20 Hertz. In practice, it has proven not possible to make measurements with the NUMIS instrument when it is within 1 to $2 \mathrm{~km}$ from power lines, even using a figure eight loop, except under optimal conditions where large amounts of detectable water are present. Also, noise reduction is expected to be less when several power lines are present, not all of which can be oriented optimally relative to the receiver loop.

\subsection{Relaxation Times}

The NMR measurement is performed by perturbing the nuclear spins out of equilibrium. The instantaneous response, immediately following the perturbation, determines the magnetization. The rate of decay of the signal, as the spins return to equilibrium, contains critical information about the soil-water system and is influenced by water content, pore size distribution, the ratio of the water filled volume of the geologic material to its pore surface area, concentration of paramagnetic ions, and ferromagnetic minerals. Extraction of the information about pore size distribution, and permeability derived from pore size distribution, is a dominant objective of NMR, borehole logging. Understanding relaxation mechanisms is perhaps more important for using NMR in groundwater investigations than in hydrocarbon reservoir engineering, because groundwater investigations are performed in a large range of geologic settings, while hydrocarbons are generally confined to sedimentary rocks.

The influence of the many factors influencing relaxation time is presently difficult to quantify. Much of the discussion must, therefore, necessarily be conceptual and qualitative. The receiver signal is schematically shown in Figure 3-7. The tipping of the protons occurs during the transmitter pulse. The duration of this excitation pulse in the NUMIS instrument can be varied from $10 \mathrm{~ms}$ to $80 \mathrm{~ms}$. The instantaneous response is by definition the response right at the end of the excitation 
pulse, and it is this response (only) that is used to determine the water content distribution. After termination of the excitation pulse, the signal decays with a characteristic decay envelope. In the instrument there is a delay time between the termination of the excitation pulse and the onset of data acquisition. In the NUMIS instrument, that delay time is $30 \mathrm{~ms}$, so that only part of the decaying signal is recorded. It is then necessary to extrapolate the measured signal back to zero time. The accuracy of that extrapolation is clearly dependent on the rate of decay (relaxation time) of water in soils and rocks. The relaxation time is defined as the time over which the signal decays to $1 / e$ (about 37\%) of its instantaneous value. For relaxation times comparable to or faster than $30 \mathrm{~ms}$, accurate extrapolation to zero time will be problematical.

The various mechanisms for relaxation advanced by NMR researchers are described next. The approach to equilibrium of the component of the net magnetization along the static field $\mathrm{Be}$ is described by the relation

$$
M_{||}(t)=M_{0}\left[1-e^{-t / T_{1}}+e^{-t / T_{1}} \cos (\theta)\right],
$$

where $M_{\|}(t)$ is the parallel component of the magnetization at time $t, M_{0}$ is the equilibrium induced magnetization, $\theta$ is the tip angle (3) [so that $M_{0} \cos (\theta)$ is the instantaneous parallel magnetization at the end of the pulse]. The relaxation time $T_{1}$ is known as the spin-lattice or longitudinal relaxation time, and governs the relaxation of net magnetization along the static field. This time constant is generally measured in controlled laboratory experiments (e.g. Hinedi et al. 1997) and in borehole logging by switching the static applied magnetic field for various lengths of time. This procedure is not possible for the surface geophysical measurements where the earth's magnetic field is used. Surface NMR imaging cannot therefore directly measure $T_{1}$.

The decaying receiver loop signal, on the other hand, is described by a different time constant $T_{2}$, known as the spin-spin or transverse relaxation time. This time constant governs the decay of the Larmor precessing components of the nuclear spins in the plane orthogonal to the static field. The decay of the transverse component of the nuclear magnetization is governed generally by different microscopic "dephasing" processes than those that govern $T_{1}$.

It is known (Kleinberg et al, 1994) that relaxation of water in bulk is very different from that of water contained in soils and rocks. The mechanisms advanced for relaxation in bulk water are interactions between different protons due to thermal motions of the water molecules, and interactions with local varying magnetic fields due to magnetic impurities in the water (e.g., ions). The concentration of paramagnetic impurities then has a strong influence on relaxation times of bulk water. Relaxation time of water in bulk can be described by a single time constant,

$$
V(t)=V_{0} e^{-t / T_{2}}
$$

where $V_{O}, V(t)$ are the voltages measured in a coil at time zero and time $\mathrm{t}$ after termination of the tipping pulse, and $T_{2}$ is the bulk transverse relaxation time which will decrease as the concentration of magnetic impurities increases.

For water in soils and rocks there is, in addition to the relaxation mechanisms listed above, relaxation due to local magnetic fields at the pore interfaces, and due to the presence of ferromagnetic minerals, such as magnetite, on the pore surfaces. The effects of ferromagnetic minerals are much stronger than those of paramagnetic ions. In fact, it is common practice in NMR logging in the oil industry to dope the drilling mud with magnetite to shorten the relaxation time of water in the drilling mud. Since water molecules in soils and rock will occur in different pore sizes, and will be found at different distances from pore surfaces and ferromagnetic impurities, the relaxation of water molecules in ground water cannot be described by a single time constant, but rather must 
be described by a distribution of time constants. The relaxation is best described by a sum of exponential decays (see, e.g. Hinedi et al. 1993).

The impact of the various parameters on the signal decay for water in soils and rocks is schematically summarized in Figure 3-8. Relaxation is expected to be short for water in clays and shales because of the large surface-to-volume ratio, short for water in soils and rocks containing ferromagnetic minerals (e.g. volcanic, granitic, metamorphic rocks), and long for water in coarse grained rocks (sands/gravels) and porous sedimentary rocks (e.g. limestone and sandstone). In soils and rocks with short relaxation times, most of the signal will have decayed before the onset of data collection in the NUMIS instrument. Water present in volcanic rocks or clays and shales will not contribute to the signal. In silts, only part of the water, that contained in large pores, will contribute to the signal. These concepts are schematically illustrated in Figure 3-9.

The delay time of an instrument, i.e., the time between termination of pulse and onset of data collection, is probably the single most important parameter detemining the value inferred from the NMR measurements for water content. In saturated, porous rock of volcanic origin (aquifers), the water content inferred may be very low, because time constants are too short to record significant signal (due to ferromagnetic minerals). In soils with little or no ferromagnetic minerals and of moderate permeability, only the fraction of water in large pores would contribute to the signal, and the water content inferred is lower than that measured by more direct means. 


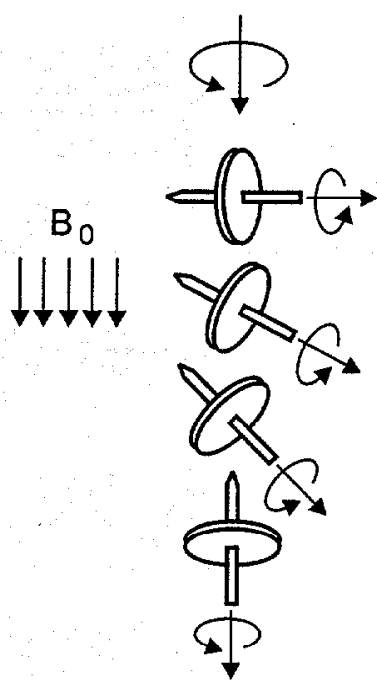

A)

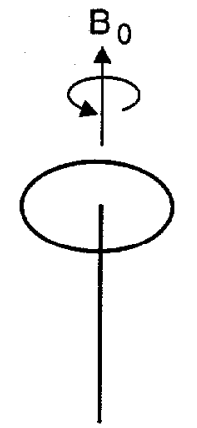

B)

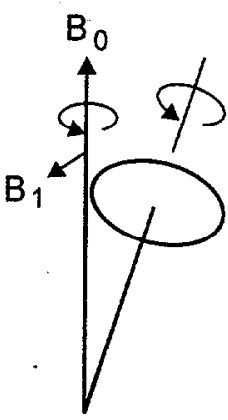

C)

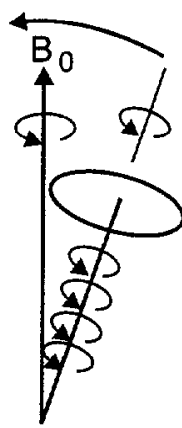

D)

Figure 3-1

Schematic illustration of behavior of magnetic moment and angular momentum of protons in the presence of externally applied magnetic fields.

A) In the presence of an external applied static magnetic field there will be slight net alignment of the magnetic moments of protons in the direction of the applied field, $\mathrm{B}_{0}$.

B) Because the proton has both a magnetic moment and an angular momentum, there also is a precession of the aligned protons about the static external field, $\mathrm{B}_{0}$. The precession frequency is the Larmor frequency.

C) When a dynamic magnetic field, $B_{1}$, is applied perpendicular to the static field, the axis of precession will tip away from the static magnetic field, $B_{0}$. The tip angle is a function of the intensity of $B_{1}$, and the duration of the applied pulse.

D) After termination of the dynamic magnetic field pulse, $B_{1}$, the protons will eventually relax back to pointing along the static applied magnetic field, $\mathrm{B}_{0}$. 

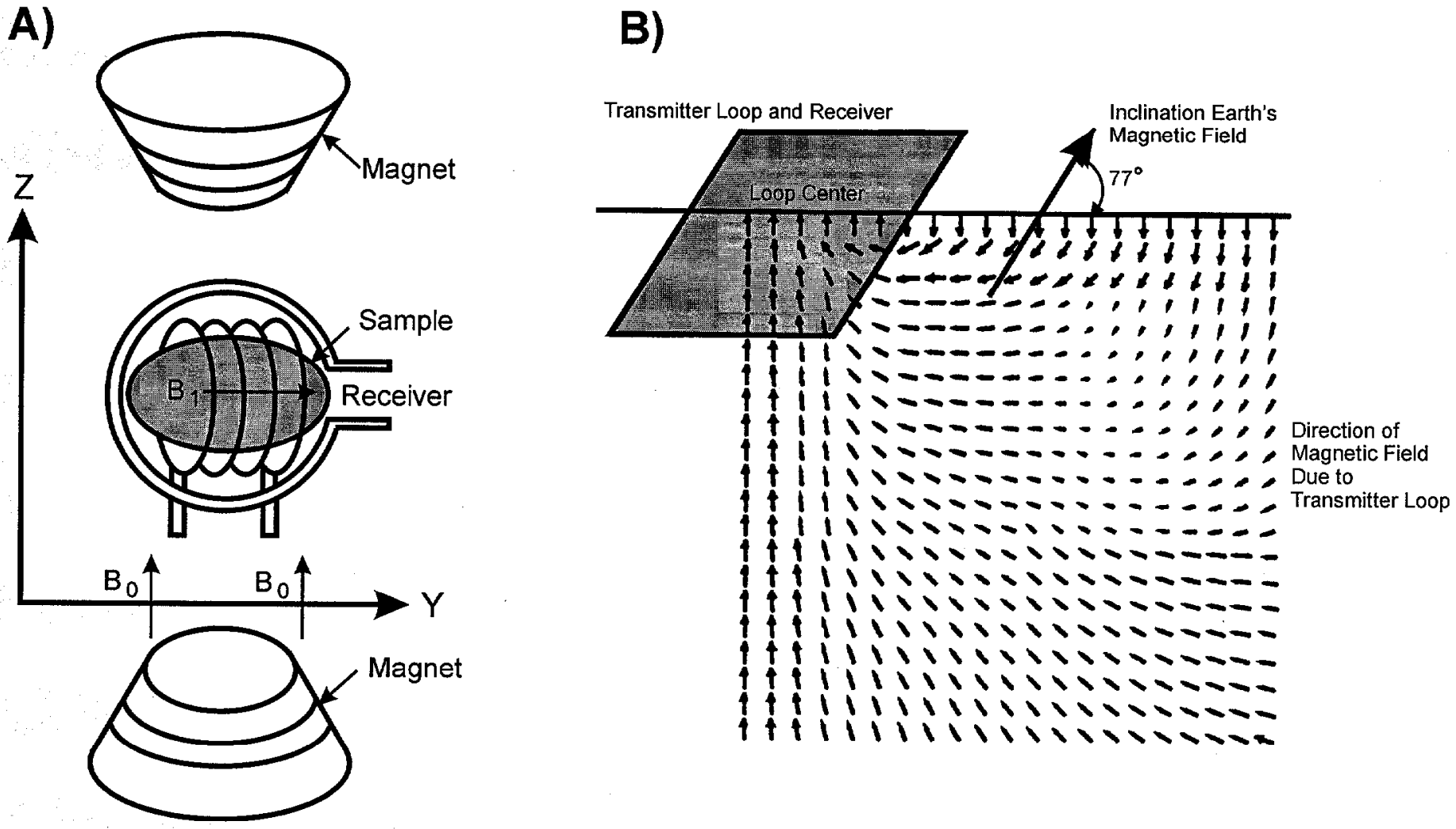

Figure 3-2

Comparison of typical NMR laboratory measurements and Surface NMR geophysical measurements.

A) In the laboratory measurement a sample is placed in the magnetic field of a strong magnet $\left(B_{0}\right)$. The dynamic magnetic field $(B$,$) is applied$ by a coil through which an alternating current (at the Larmor frequency) is driven creating a dynamic magnetic field perpendicular to the static magnetic field.

B) In the geophysical experiment the static magnetic field is the Earth's magnetic field. The dynamic magnetic field (at the Larmor frequency) is generated by a transmitter loop at the surface. The magnetic field of the transmitter loop has a component perpendicular to the static Earth's magnetic field dependent on location in the subsurface. 


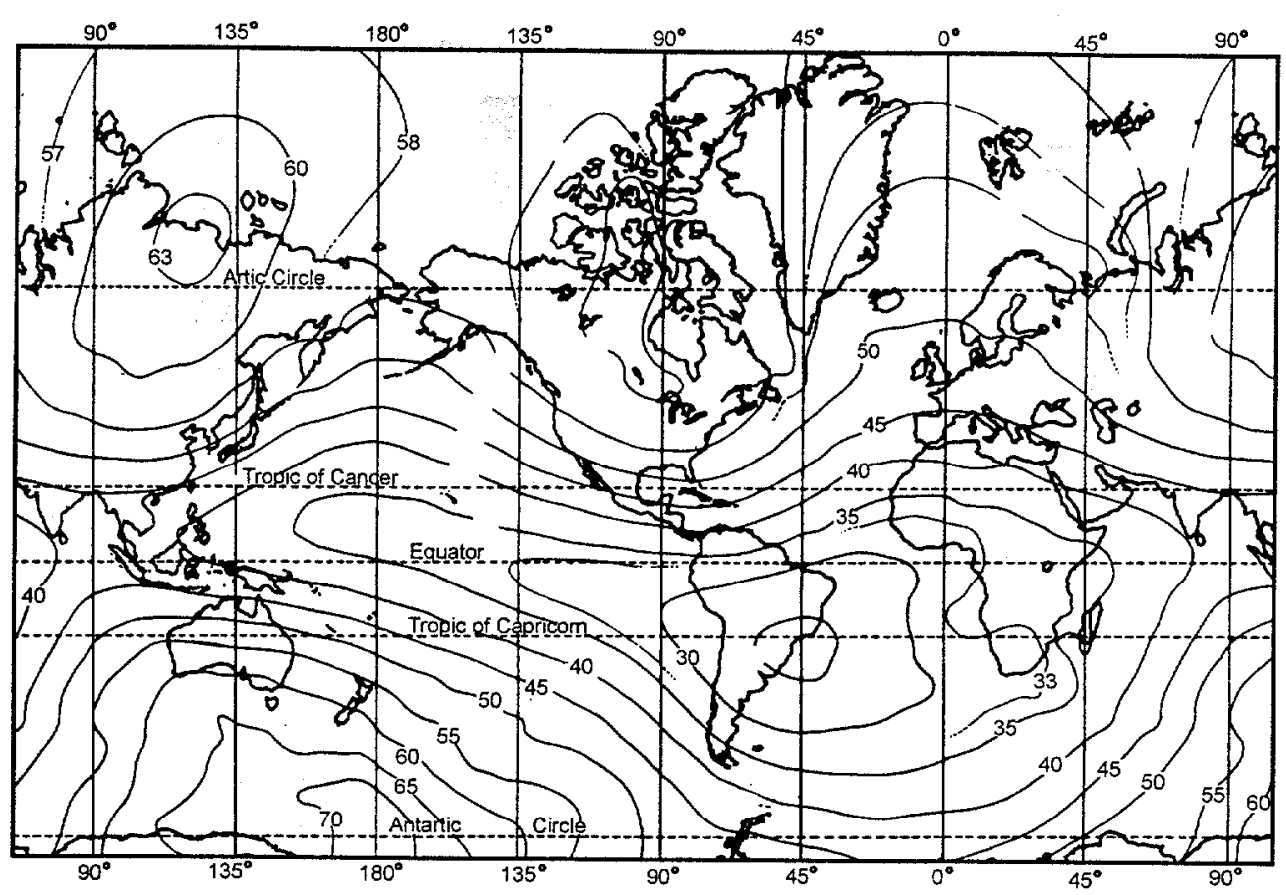

A) The Total Intensity of the Earth's magnetic Field

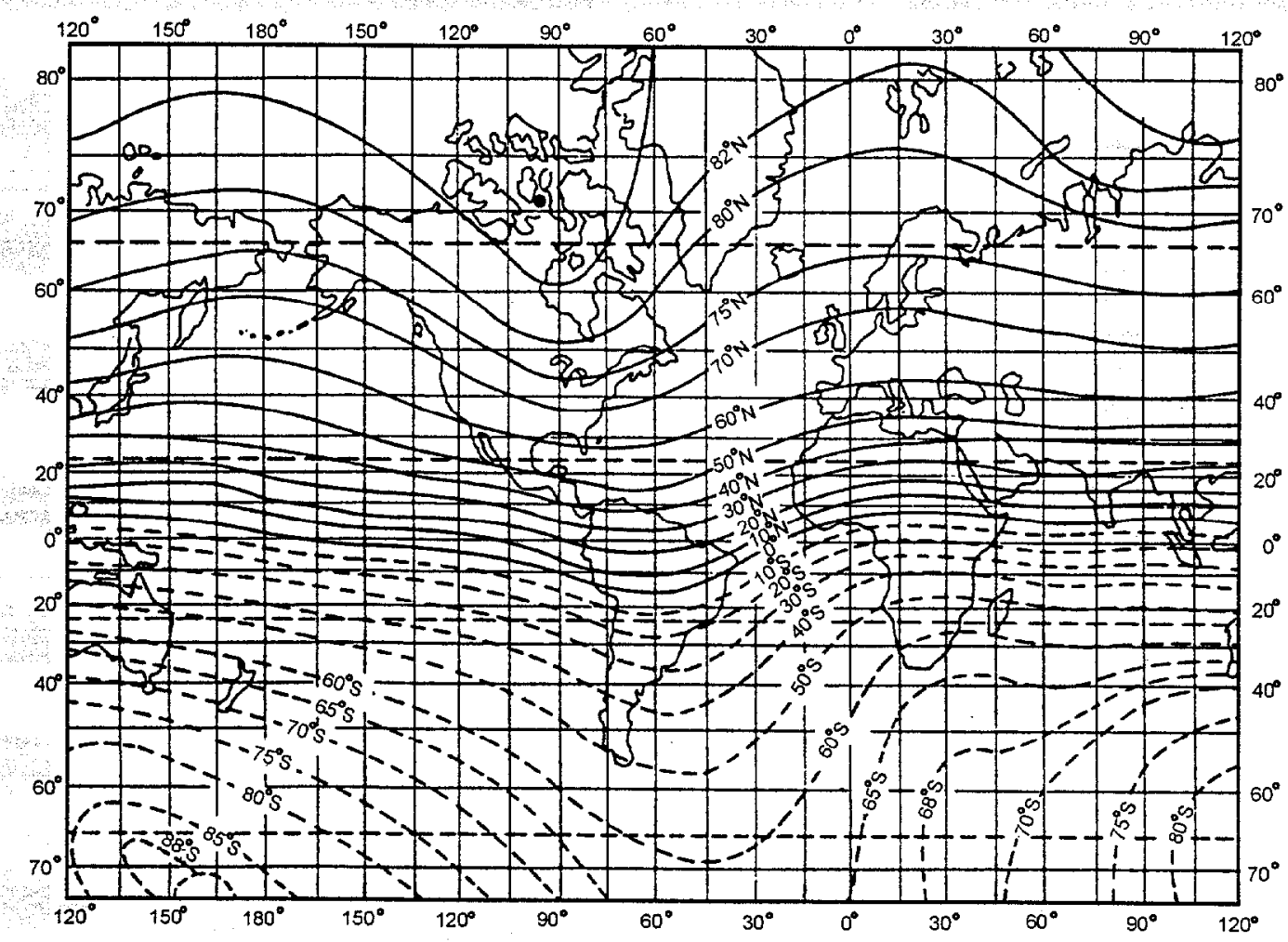

B) The Geomagnetic Inclination in Degrees of Arc from the Horizontal

Figure 3-3

The intensity and inclination of the Earth's magnetic field

A) The total field intensity in thousand gammas (one gamma is $10^{-5}$ gauss).

The intensity is about 55,000 gammas ( 0.55 gauss).

B) The inclination of the Earth magnetic field. 


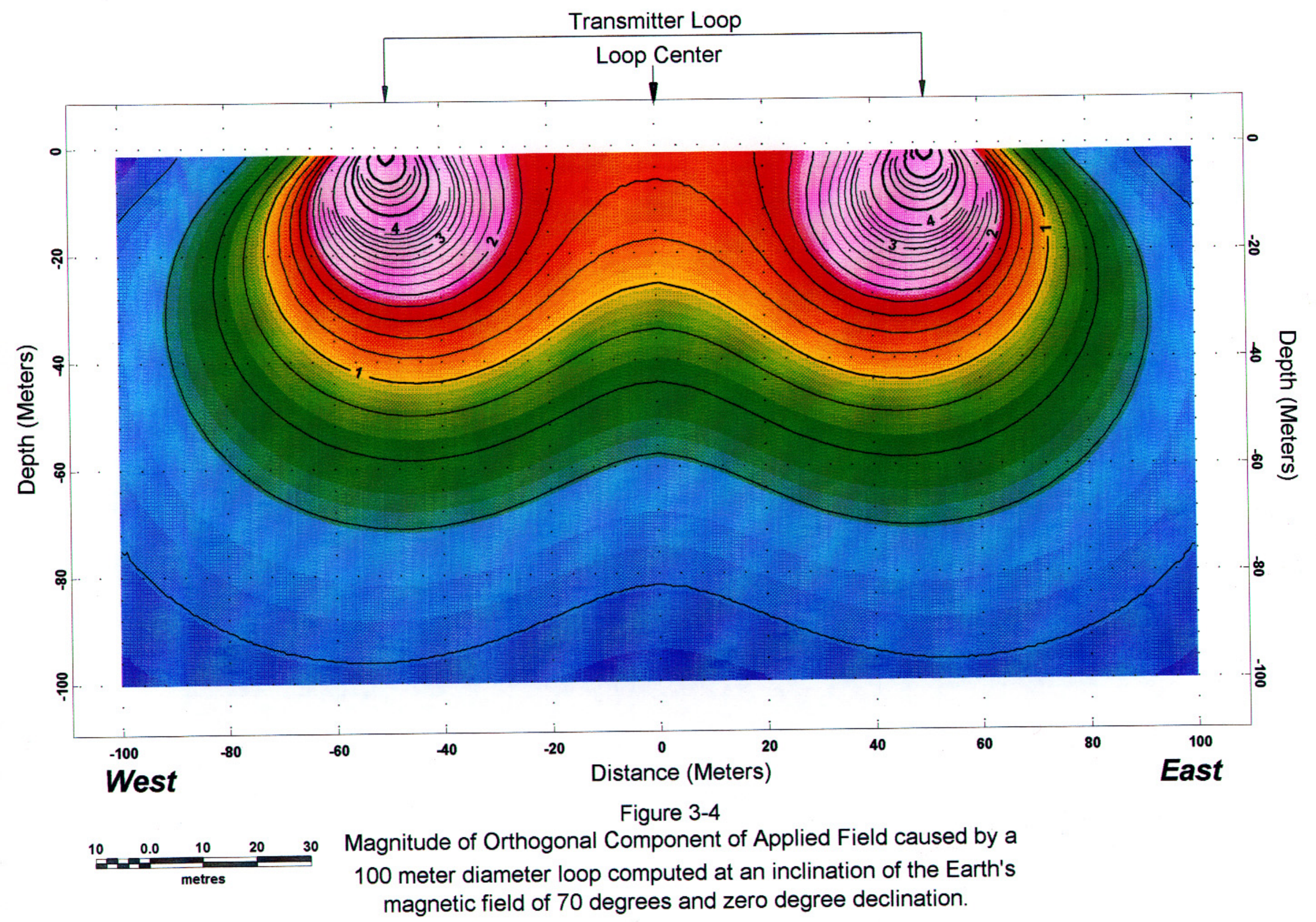




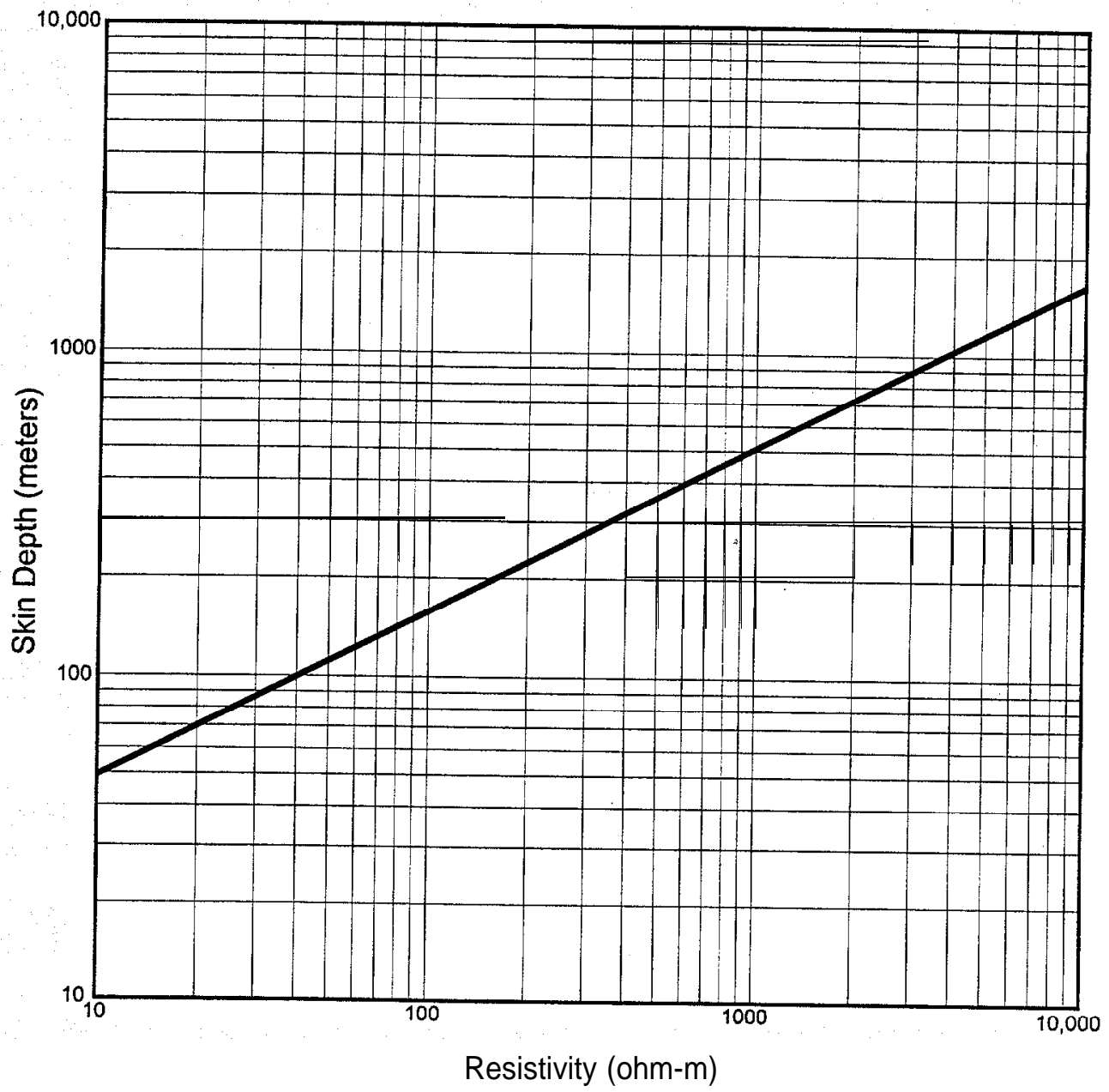

Figure 3-5

Skin depth of electromagnetic radiation at 2,000 hertz 

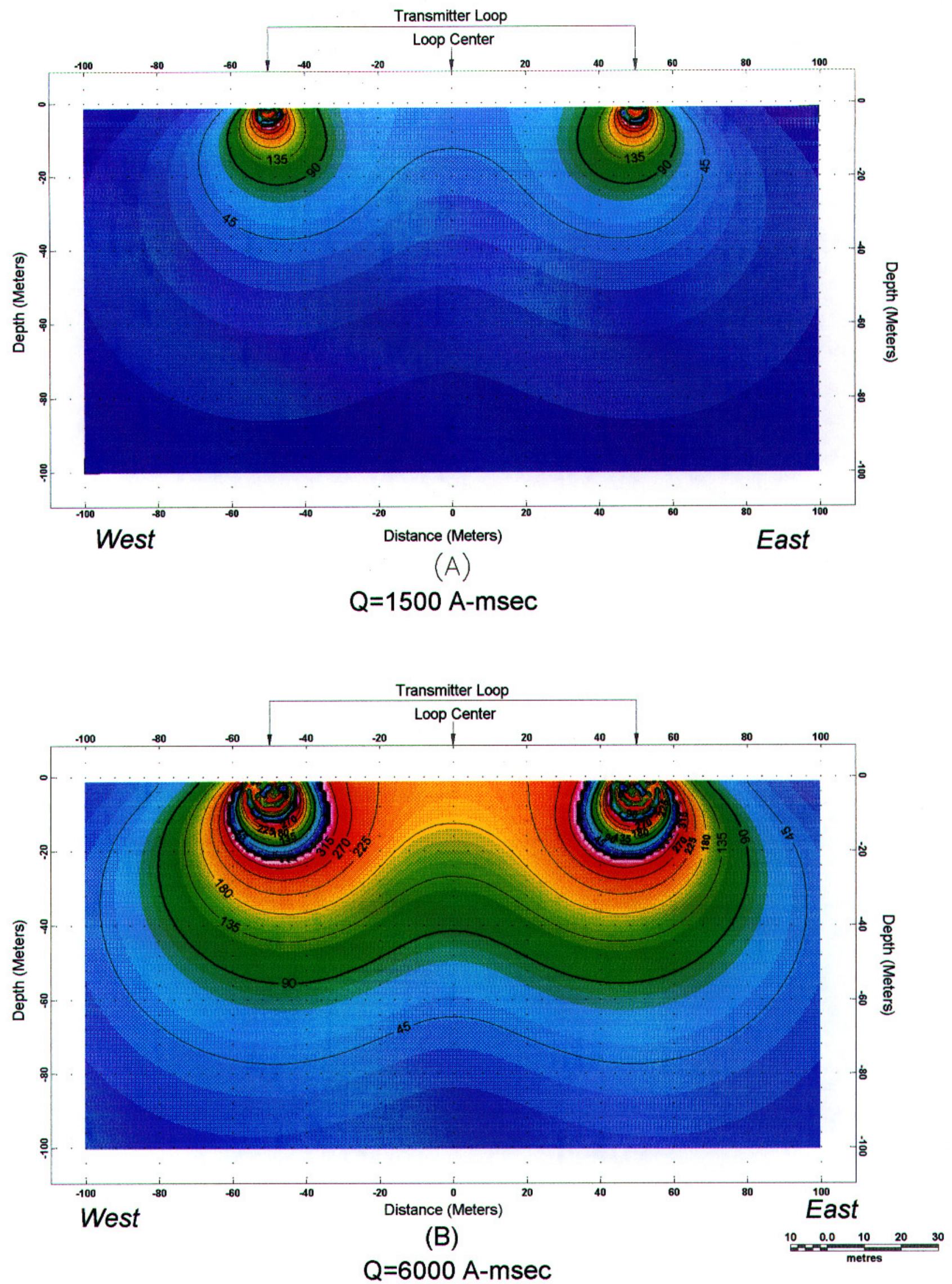

Figure 3-6

Tipping angle in degrees at two pulse moments, computed for a $100 \mathrm{~m}$ diameter circular transmitter loop at an inclination of the Earth's magnetic field of 70 degrees, and zero degree declination. 


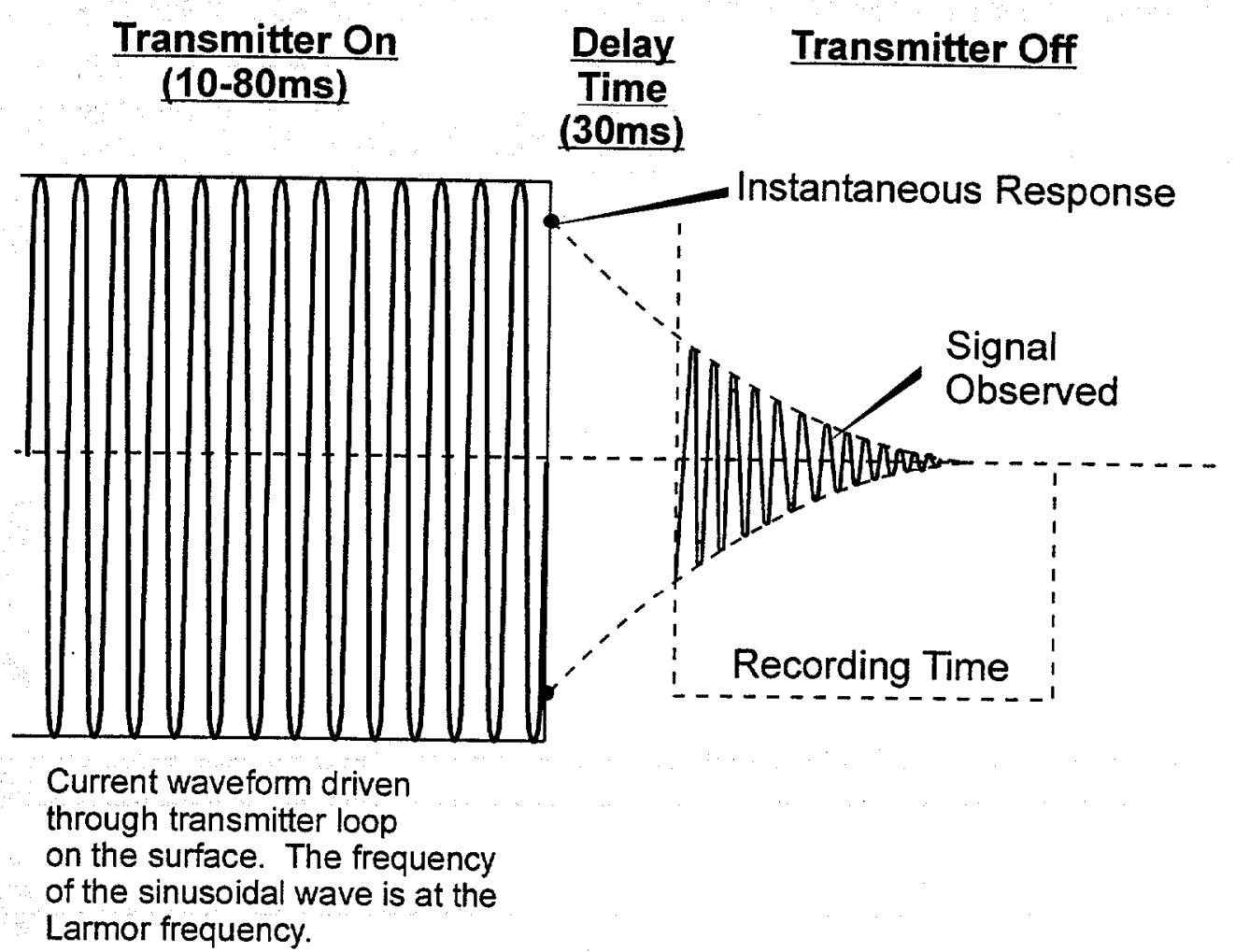

Figure 3-7

System Waveforms of Numis Systems 


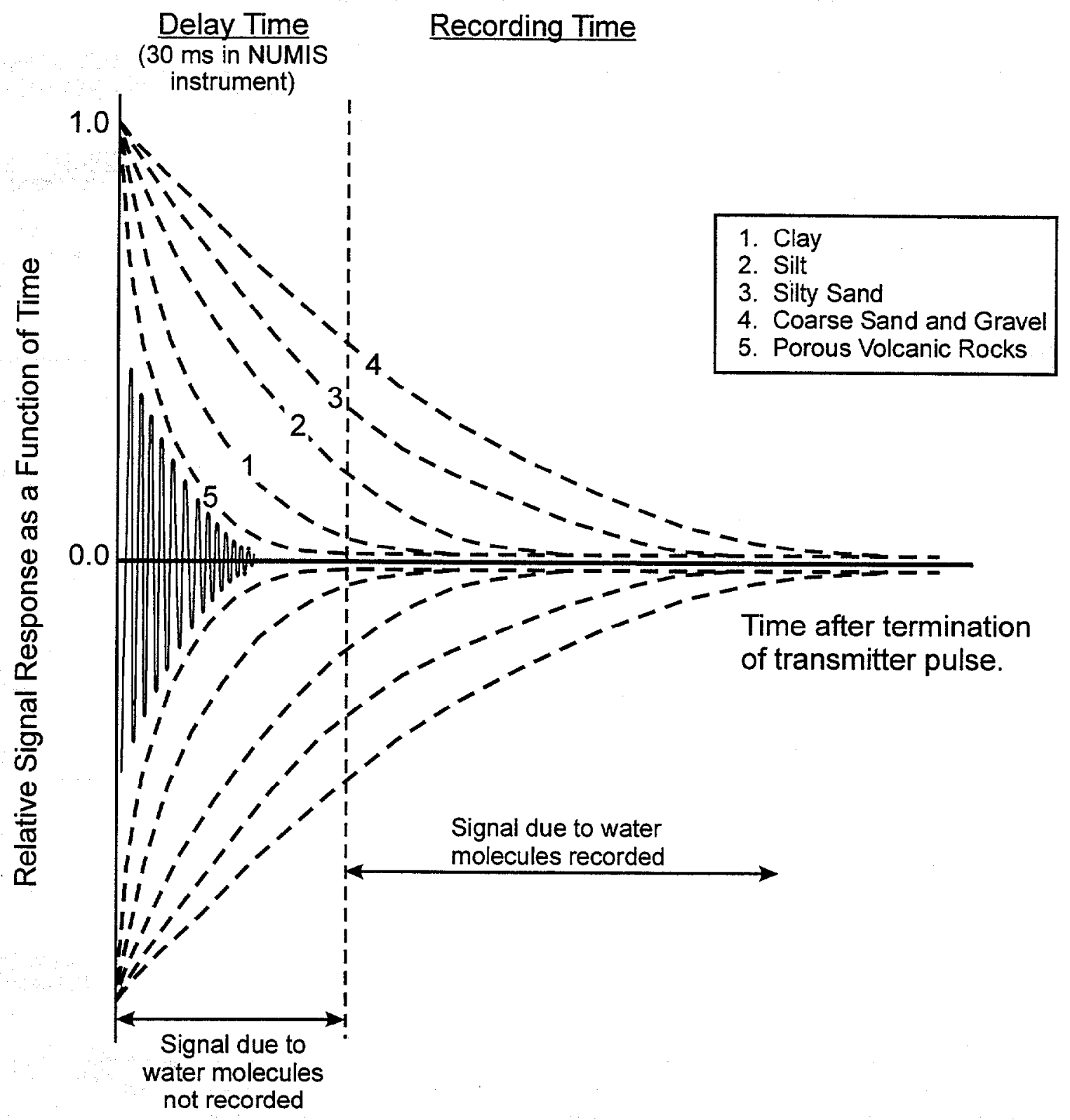

Figure 3-8

Schematic illustration of envelope of signal at Larmor frequency.

The delay time of the NUMIS instruments $(30 \mathrm{~ms})$ results in recording only part of the signal. The delay time of water in clay, silts, and volcanic rocks may be too fast to result in a measurable signal. To infer water content in the coarse sands and gravel the signal must be extrapolated to zero time. 


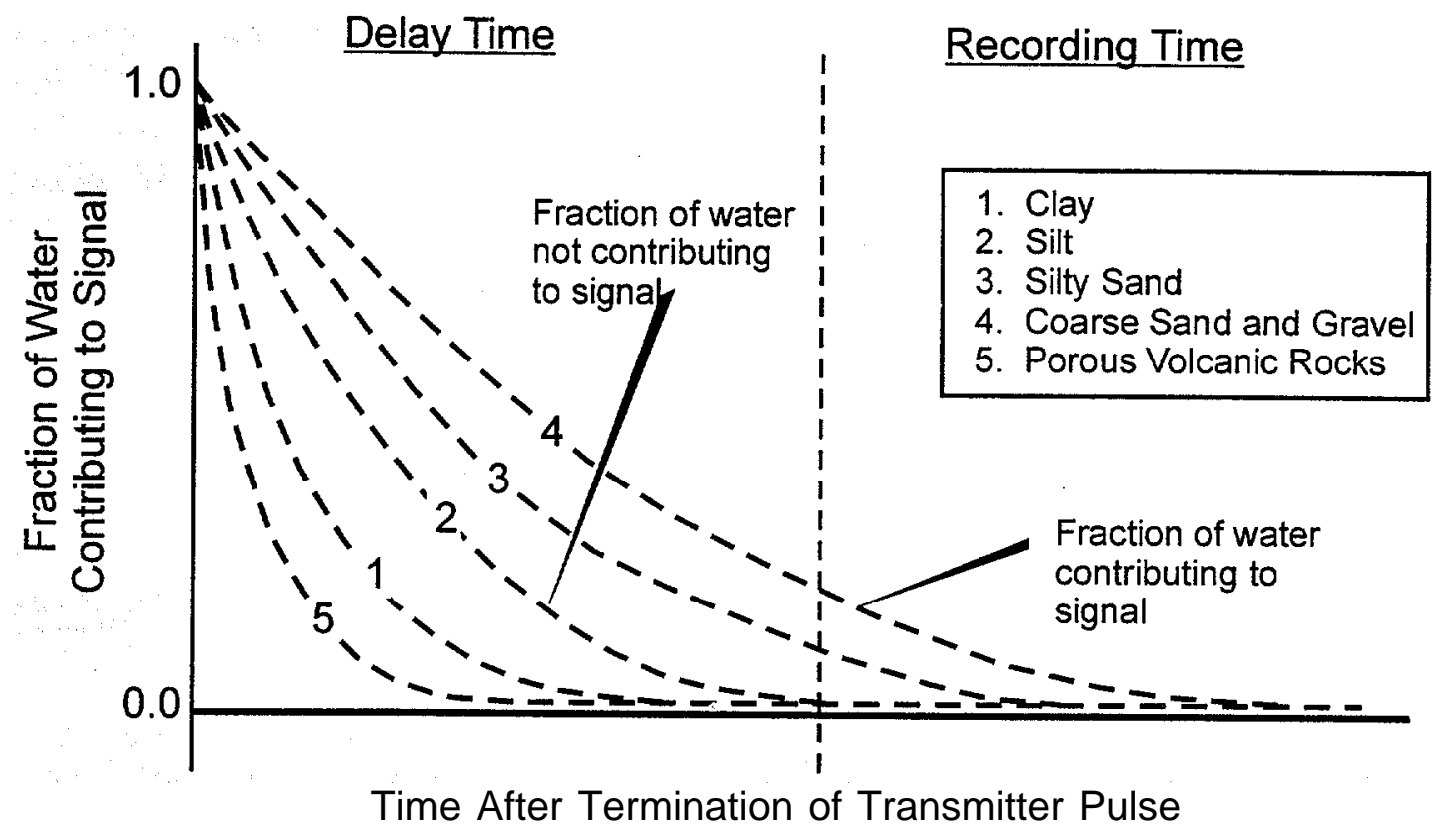

Figure 3-9

Fraction of water in several soil and rock type contributing to measured NMR signal. 


\section{THE NUMIS INSTRUMENT}

Figure 4-1 shows a block diagram, and Figure 4-2 shows a photograph of the NUMIS NMR instrument components. The design features are largely dictated by the fact that a nanovolt level signal must be resolved. The equipment has a transmitter and a receiver function, and the same antenna loop is used for transmitting and receiving.

The antenna configurations used in the present work are circular loops, square loops, and figure eight loops. The geometry and dimensions of the loops determine to a large the extent effective exploration depths. The transmitter loop wire is insulated, stranded copper wire with a cross-section of $25 \mathrm{~mm}$. The resistance of this wire is $0.2 \Omega$ per $100 \mathrm{~m}$ and weight is $40 \mathrm{~kg}$ per $100 \mathrm{~m}$. The total weight of a $100 \mathrm{~m}$ diameter circular loop or a $50 \mathrm{~m}$ diameter figure eight loop is then about $125 \mathrm{~kg}$. The system waveforms are shown in Figure 3-7. Pulses of varying current (from a few amperes to about 300 amperes), at the Larmor frequency (varying from 2 - $2.5 \mathrm{kHz}$ ) are transmitted. An important parameter of the system waveform is the delay time between termination of the excitation pulse and the time the receiver starts recording. For the NUMIS instrument, this delay time is about $30 \mathrm{~ms}$. This relatively large delay time has a major influence on the measured water content, and appears to be required mainly for switching the microprocessor from transmitter to receiver status, and not due to ringing in the coil (expected to endure for perhaps $15 \mathrm{~ms}$ ).

The power supply for the function generator is two 12 volt car batteries connected in series. These batteries are used to charge capacitors which then discharge through a function generator that converts the DC discharge current into alternating current pulses at a tunable Larmor frequency. The PC microprocessor controls the function generator. The maximum output current is typically 200-300 A, and the maximum output voltage is about 3,000 V. Pulse moments, the product of pulse duration and current, can be varied from 300 to 9,000 A-ms. The rationale for using batteries as a power source is that the groundwater signal is so small (in the nanovolt range\}, that the electromagnetic noise from gas powered generators cannot presently be accommodated.

The same loop is used for transmitting the excitation current and for measuring the voltage induced by the precessing spins. After the excitation current is switched off, a relay connects the antenna loop to the receiving circuit. The received signal decays with a carrier frequency at the Larmor frequency. The received signal is amplified and a number of recordings are stacked to improve the signal to noise ratio. 


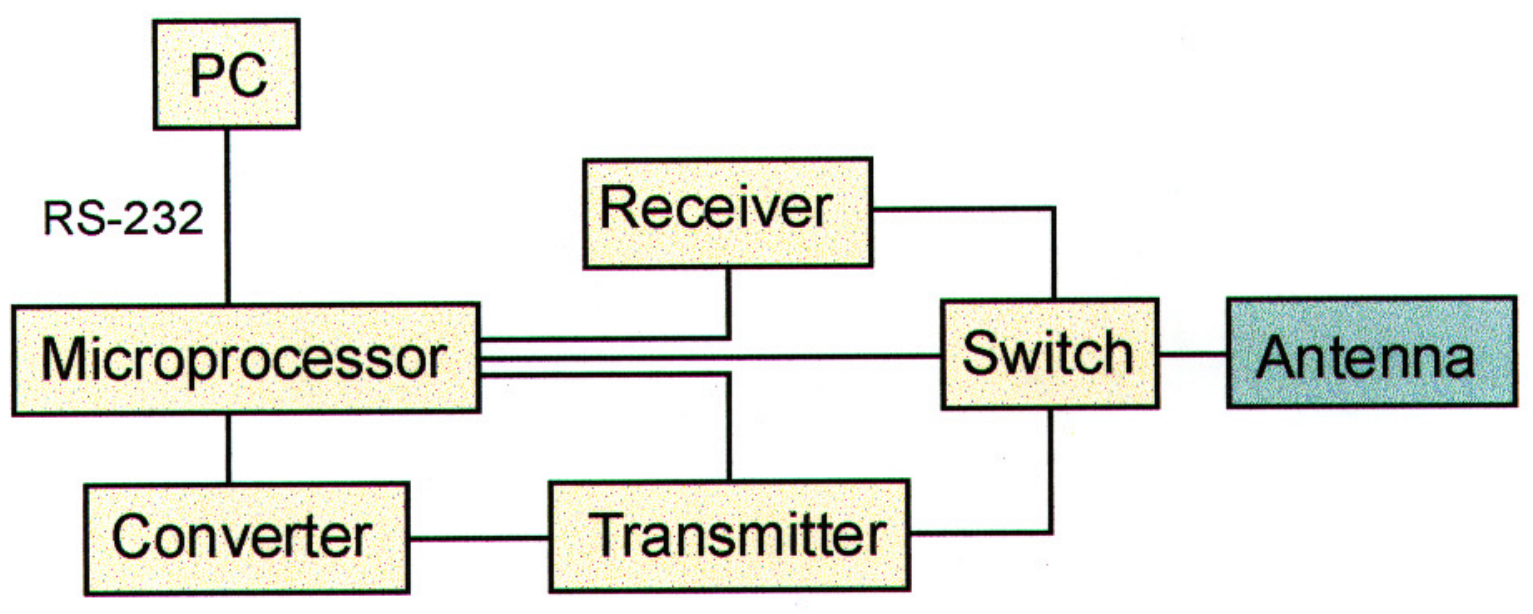

Figure 4-1: Schematic diagram of NUMIS equipment

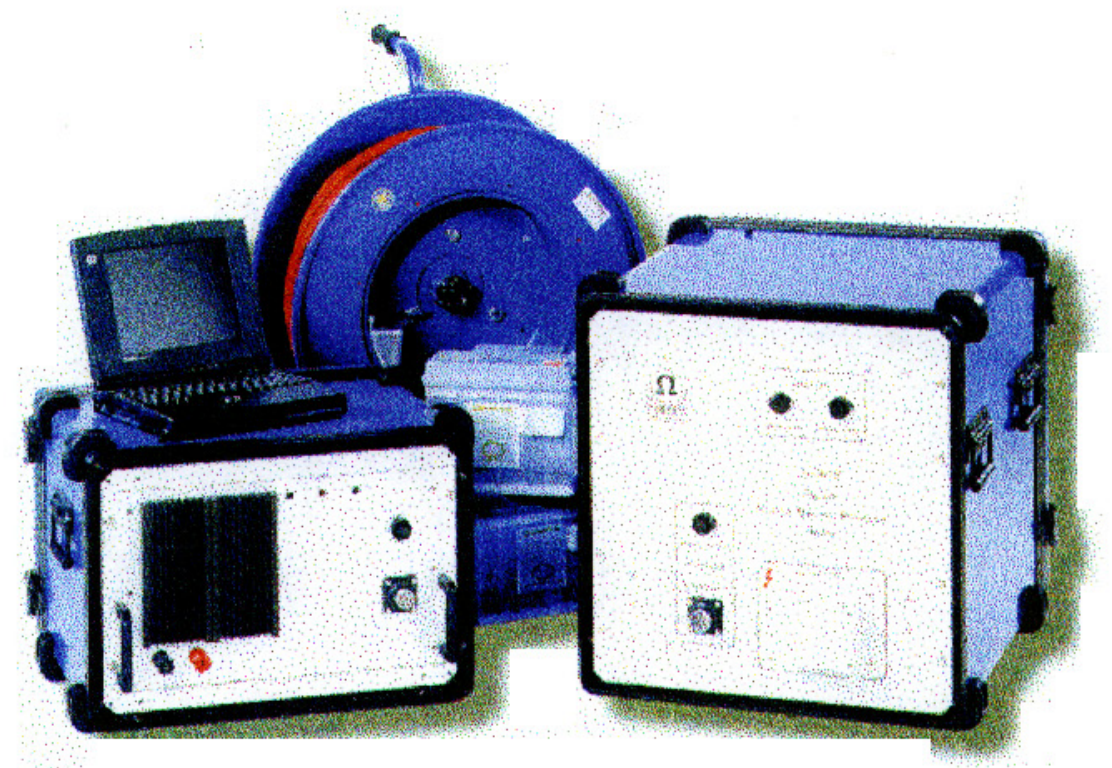

Figure 4-2: Photo of Numis equipment 


\section{DATA ACQUISITION AND PROCESSING}

\subsection{Determination of the Larmor Frequency}

The first critical step in data acquisition is to determine the Larmor frequency. The Larmor frequency is determined by the strength of the earth's magnetic field and is a function of location. The Earth's field was measured at each station by a Proton Precession Magnetometer. The Larmor frequency in Hertz is given by

$$
\nu_{L}=\omega_{l} / 2 \pi=0.0426 B_{0},
$$

in which $\boldsymbol{B}_{\boldsymbol{o}}$ is in nanoTesla. For example, the Earth's magnetic field in the vicinity of Socorro, New Mexico, is about 50,500 nT (0.505 gauss) yielding a Larmor frequency of about 2150 Hertz. The inclination of the Earth's magnetic field at Socorro, New Mexico, is about $67^{\circ}$ from the horizontal. This inclination has no impact on the Larmor frequency, but does have an influence on the water content measurement since it determines the component of the ac magnetic field perpendicular to the Earth's magnetic field. During data acquisition, the diurnal variation in the magnetic field is also recorded. In case of substantial diurnal drift, an average value is entered for the Larmor frequency.

\subsection{Instrument Calibration}

After entering an estimate for the Larmor frequency into the PC Microprocessor, the equipment is further adjusted to find the actual Larmor frequency by maximizing the signal. It is one of the troublesome aspects of the present measurement that the Larmor frequency derived from an accurate measurement of the Earth's magnetic field may differ by several Hertz from the Larmor frequency selected by the instrument. This is due to the fact that the magnetic permeability of the ground is slightly different from that of the air.

\subsection{Selection of Acquisition Parameters}

Other parameters selected prior to acquisition are the number of stacks, the number of pulse moments to be recorded, and the dimensions and configurations of the antenna loops. After these parameters have been selected, the PC microprocessor controls the data acquisition.

\subsection{Acquisition Process, Signal Stacking, and Recording}

In order to derive water content as a function of depth, measurements must be made over a range of pulse moments. The depth from which maximum signal contribution is derived typically increases with pulse moment (see, e.g., Figure 7-1). Typically, measurements are made at 16 pulse moments that may be varied from 200 A-ms to 9,000 A-ms. A cycle of measurements from one stack consists of the following steps:

- Charging Capacitors

- Noise Measurement Before Stack

- Current Pulse Generation

- Delay Time for Switching from Transmitter to Receiver

- Signal Measurement 
- Data Transmission

These steps require approximately eight seconds per stack, so that measurement time for 32 stacks for 16 pulse moments requires 75 minutes. During the acquisition process, diagnostic information about data quality and progress of the acquisition process is available.

\subsection{Data Processing and Interpretation}

The data used in inversion and interpretation is mainly the signal amplitude as a function of pulse moment (see, e.g., Figure 7-1). This function contains all information about water content distribution versus depth. The mathematical formulation of the inversion process to derive water content versus depth is given in Appendix B.

Inversion of the data into water content versus depth proceeds along the following steps:

- Computing the component of the magnetic field perpendicular to the local Earth's magnetic field caused by the transmitter loop as a function of depth. This magnetic field can be computed for ground stratified in resistivity with depth.

- Inverting the imaging formula to infer the water distribution that would give rise to the measured receiver voltage data. 


\section{DESCRIPTION OF MEASUREMENT SITES}

In this section a brief tabulation of the geological and hydrological character, as well as the NMR data quality, found at each of the measurement sites is given. More extensive details are contained in Appendix A.

\subsection{Colorado}

Experimental sites were selected in Colorado and New Mexico. The sites in Colorado were all located around Denver, so that the equipment could be evaluated, tested and calibrated without significant travel costs. The site locations are shown on Figure 6-1 and are listed in Table 6-1.

\begin{tabular}{|c|c|c|c|c|c|c|}
\hline \multicolumn{7}{|c|}{$\begin{array}{c}\text { Table 6-1 } \\
\text { Signal and Ambient Electromagnetic Noise } \\
\text { Observed at sites in COLORADO } \\
\text { (Data From Figure Eight Loop Types) }\end{array}$} \\
\hline $\begin{array}{l}\text { Site No. } \\
\text { \& Name } \\
\text { (See } \\
\text { Fig. 6-1) }\end{array}$ & Sounding & $\begin{array}{l}\text { Ave. } \\
\text { Peak } \\
\text { Signal } \\
\text { (nV) }\end{array}$ & $\begin{array}{l}\text { Ave. } \\
\text { Noise } \\
(\mathrm{nV})\end{array}$ & $\begin{array}{l}\text { Physio- } \\
\text { graphic } \\
\text { Area/ } \\
\text { Geology }\end{array}$ & $\begin{array}{l}\text { GW } \\
\text { Depth } \\
(\mathbf{m})\end{array}$ & Comments \\
\hline $\begin{array}{c}\text { 1/Bear } \\
\text { Creek }\end{array}$ & $\begin{array}{l}\text { Bear } 1 \\
\text { through } \\
\text { Bear } 3\end{array}$ & 10 & $<200$ & $\begin{array}{l}\text { Denver Basin, } \\
\text { Shales and } \\
\text { Clays }\end{array}$ & $\approx 1$ & $\begin{array}{l}\text { Good Sounding } \\
\text { Low Noise } \\
\text { No Signigicant NMR } \\
\text { Water Signature }\end{array}$ \\
\hline $\begin{array}{c}\text { 2/Clear } \\
\text { Creek }\end{array}$ & $\begin{array}{l}\text { Clear } 1 \\
\text { and } \\
\text { Clear } 6\end{array}$ & 50 & $>1000$ & $\begin{array}{l}\text { Denver Basin, } \\
\text { Gravels and } \\
\text { Sands Near } \\
\text { Surface }\end{array}$ & $\approx 1$ & $\begin{array}{l}\text { Bad Sounding } \\
\text { High Noise } \\
\text { Low NMR Signal }\end{array}$ \\
\hline $\begin{array}{c}\text { 3/Prospect } \\
\text { Park }\end{array}$ & $\begin{array}{l}\text { Prosp } 1 \\
\text { and } \\
\text { Prosp } 4\end{array}$ & 20 & $>500$ & $\begin{array}{l}\text { Denver Basin, } \\
\text { Shales and } \\
\text { Clays }\end{array}$ & $\overline{1}$ & $\begin{array}{l}\text { Fair Sounding } \\
\text { Relatively High Noise } \\
\text { No Significant NMR } \\
\text { Water Signature }\end{array}$ \\
\hline $\begin{array}{c}\text { 4/Cherry } \\
\text { Creek }\end{array}$ & $\begin{array}{c}\text { Cherry } 2 \\
\text { through } \\
\text { Cherry } 22\end{array}$ & $>100$ & $<500$ & $\begin{array}{l}\text { Denver Basin, } \\
\text { Sands and } \\
\text { Gravels Near } \\
\text { Surface }\end{array}$ & 3 to 6 & $\begin{array}{l}\text { Good Soundings } \\
\text { Moderate Noise } \\
\text { Good NMR Water } \\
\text { Signature }\end{array}$ \\
\hline
\end{tabular}

The sites are located in the Denver Basin, which is a sedimentary basin consisting of shales and sandstone sequences. Shallow (upper $100 \mathrm{~m}$ ) aquifers are mainly found in paleo-channels filled with coarse grained sediments eroded in the Denver formation. The surface NMR measurements at Cherry Creek are made across such a paleo-channel. The sites are located in parks, and an effort was made to select locations away from power lines. Nevertheless, at one of the four sites, Clear Creek, high ambient noise prevented recording data of acceptable quality. The data acquisition in Colorado showed the importance of selecting sites at 1 to $2 \mathrm{~km}$ from power lines in cases where the NMR water signal is low, and this experience became a critical criterion for subsequent site selection in New Mexico. 


\section{$6.2 \mathrm{New}$ Mexico}

Measurements in Colorado showed that deriving water content from NMR signals is site specific and depends on a number of factors of a soil-water system. It was therefore decided to select sites in New Mexico over a wide range of hydrogeologic settings. The NMR sites selected in New Mexico are shown in Figure 6-2 and are listed in Table 6-2.

\begin{tabular}{|c|c|c|c|c|c|c|}
\hline \multicolumn{7}{|c|}{$\begin{array}{c}\text { Table 6-2 } \\
\text { Signal and Ambient Electromagnetic Noise } \\
\text { Observed at Sites in NEW MEXICO } \\
\text { (Data From Figure Eight Loop Types) }\end{array}$} \\
\hline $\begin{array}{l}\text { Site No. } \\
\text { \& Name } \\
\quad \text { (See } \\
\text { Fig. 6-2) }\end{array}$ & Sounding & $\begin{array}{l}\text { Ave. } \\
\text { Peak } \\
\text { Signal } \\
\text { (nV) }\end{array}$ & $\begin{array}{l}\text { Ave. } \\
\text { Noise } \\
(\mathrm{nV})\end{array}$ & $\begin{array}{l}\text { Physio- } \\
\text { graphic } \\
\text { Area/ } \\
\text { Geology }\end{array}$ & $\begin{array}{c}\text { GW } \\
\text { Depth } \\
(\mathbf{m})\end{array}$ & Comments \\
\hline $\begin{array}{c}\text { 1/Rio } \\
\text { Salado }\end{array}$ & SALAD1 & $<10$ & 50 & $\begin{array}{l}\text { Rio Grande } \\
\text { Valley, } \\
\text { Quaternary } \\
\text { Deposits }\end{array}$ & $\begin{array}{l}\text { Estimated } \\
3 \text { meters }\end{array}$ & $\begin{array}{l}\text { Good Sounding, } \\
\text { Very Low Noise, } \\
\text { No NMR } \\
\text { Water Signal }\end{array}$ \\
\hline $\begin{array}{c}\text { 2/Sevilleta - } \\
\text { Chi Site }\end{array}$ & $\begin{array}{l}\mathrm{CH} 1 \\
\text { and } \\
\mathrm{CH} 2\end{array}$ & $<5$ & $<200$ & $\begin{array}{l}\text { Rio Grande } \\
\text { Valley, } \\
\text { Quaternary } \\
\text { Deposits }\end{array}$ & $\begin{array}{l}\text { Measured } \\
2 \text { meters }\end{array}$ & $\begin{array}{l}\text { Good Sounding, } \\
\text { Low Noise, } \\
\text { No NMR } \\
\text { Water Signal }\end{array}$ \\
\hline $\begin{array}{l}\text { 3/Bosque } \\
\text { Del } \\
\text { Apache }\end{array}$ & $\begin{array}{l}\text { SB5A } \\
\text { and } \\
\text { SB5B }\end{array}$ & 20 & $<200$ & $\begin{array}{l}\text { Rio Grande } \\
\text { Valley, } \\
\text { Quaternary } \\
\text { Deposits }\end{array}$ & $\begin{array}{c}\text { Measured } \\
3 \text { meters }\end{array}$ & $\begin{array}{l}\text { Good Sounding, } \\
\text { Low Noise, } \\
\text { No NMR } \\
\text { Water Signal }\end{array}$ \\
\hline $\begin{array}{c}\text { 4/Elephant } \\
\text { Butte } \\
\text { Reservoir }\end{array}$ & ELEP & 20 & $<100$ & $\begin{array}{l}\text { Rio Grande } \\
\text { Valley, } \\
\text { Quaternary } \\
\text { Deposits }\end{array}$ & $\begin{array}{c}\text { Estimated } \\
\text { Less Than } \\
5 \text { meters }\end{array}$ & $\begin{array}{l}\text { Good Sounding, } \\
\text { Low Noise, } \\
\text { No NMR } \\
\text { Water Signal }\end{array}$ \\
\hline $\begin{array}{l}\text { 5/Contreras - } \\
\text { Well 99, NM }\end{array}$ & $\overline{C 99}$ & 35 & $<200$ & $\begin{array}{l}\text { Rio Grande } \\
\text { Valley, } \\
\text { Quaternary } \\
\text { Deposits }\end{array}$ & $\begin{array}{l}\text { Estimated } \\
10 \text { meters }\end{array}$ & $\begin{array}{l}\text { Fair Sounding, } \\
\text { Low Noise, } \\
\text { No NMR } \\
\text { Water Signal }\end{array}$ \\
\hline $\begin{array}{c}\text { 6/Los } \\
\text { Ojuelos } \\
\text { Springs }\end{array}$ & OJSP1 & 40 & $<100$ & $\begin{array}{l}\text { Rio Grande } \\
\text { Valley, } \\
\text { Quaternary } \\
\text { Deposits }\end{array}$ & $\begin{array}{l}\text { Estimated } \\
5 \text { meters }\end{array}$ & $\begin{array}{l}\text { Good Sounding, } \\
\text { Low Noise, } \\
\text { Small NMR } \\
\text { Water Signal }\end{array}$ \\
\hline $\begin{array}{c}7 / \text { Isleta } \\
\text { Lakes }\end{array}$ & ISLETA & $30-50$ & 200 & $\begin{array}{l}\text { Rio Grande } \\
\text { Valley, } \\
\text { Quaternary } \\
\text { Deposits }\end{array}$ & $\begin{array}{l}\text { Estimated } \\
1 \text { meter }\end{array}$ & $\begin{array}{l}\text { Poor Sounding, } \\
\text { Moderate Noise, } \\
\text { Small NMR } \\
\text { Water Signal }\end{array}$ \\
\hline
\end{tabular}




\begin{tabular}{|c|c|c|c|c|c|c|}
\hline \multicolumn{7}{|c|}{$\begin{array}{c}\text { Table 6-2 (cont.) } \\
\text { NEW MEXICO SITES }\end{array}$} \\
\hline $\begin{array}{c}\text { Site No. } \\
\text { \& Name } \\
\text { (See } \\
\text { Fig. 6-2) } \\
\end{array}$ & Sounding & $\begin{array}{l}\text { Ave. } \\
\text { Peak } \\
\text { Signal } \\
(\mathrm{nV})\end{array}$ & $\begin{array}{c}\text { Ave. } \\
\text { Noise } \\
(\mathrm{nV})\end{array}$ & $\begin{array}{l}\text { Physio- } \\
\text { graphic } \\
\text { Area/ } \\
\text { Geology } \\
\end{array}$ & $\begin{array}{c}\text { GW } \\
\text { Depth } \\
(\mathrm{m})\end{array}$ & Comments \\
\hline $\begin{array}{l}\text { 8/Santa } \\
\text { Rosa } \\
\text { Lake }\end{array}$ & ROSA & 30 & $<200$ & $\begin{array}{l}\text { Pecos River } \\
\text { Valley, } \\
\text { Quaternary } \\
\text { Deposits }\end{array}$ & $\begin{array}{l}\text { Estimated } \\
1 \text { meter }\end{array}$ & $\begin{array}{l}\text { Good Sounding, } \\
\text { Low Noise, } \\
\text { Small NMR } \\
\text { Water Signal }\end{array}$ \\
\hline $\begin{array}{l}\text { 9/Lea } \\
\text { Lake }\end{array}$ & $\begin{array}{l}\text { LEA1 } \\
\text { and } \\
\text { LEA2 }\end{array}$ & $>200$ & $<200$ & $\begin{array}{l}\text { Pecos River } \\
\text { Valley, Permian } \\
\text { Limestone } \\
\text { and Gypsum }\end{array}$ & $\begin{array}{l}\text { Measured } \\
0.7 \text { meters }\end{array}$ & $\begin{array}{l}\text { Excellent } \\
\text { Sounding, } \\
\text { Low Noise, } \\
\text { High NMR } \\
\text { Water Signal }\end{array}$ \\
\hline 10/Artesia & ARTW3 & 70 & $<150$ & $\begin{array}{l}\text { Pecos River } \\
\text { Valley, } \\
\text { Quaternary } \\
\text { Alluvium } \\
\end{array}$ & $\begin{array}{l}\text { Estimated } \\
5 \text { to } 10 \\
\text { meters }\end{array}$ & $\begin{array}{l}\text { Poor Sounding, } \\
\text { Low Noise, } \\
\text { Moderate NMR } \\
\text { Water Signal } \\
\end{array}$ \\
\hline 11/Dexter & DEXTER1 & 20 & 200 & $\begin{array}{l}\text { Pecos River } \\
\text { Valley, } \\
\text { Quaternary } \\
\text { Alluvium }\end{array}$ & $\begin{array}{l}\text { Estimated } \\
21 \text { meters }\end{array}$ & $\begin{array}{l}\text { Good Sounding, } \\
\text { Moderate Noise, } \\
\text { Low NMR } \\
\text { Water Signal }\end{array}$ \\
\hline $\begin{array}{l}\text { 12/Lake } \\
\text { Arthur }\end{array}$ & LAKEA1 & 30 & $<100$ & $\begin{array}{l}\text { Pecos River } \\
\text { Valley, } \\
\text { Quaternary } \\
\text { Alluvium }\end{array}$ & $\begin{array}{l}\text { Estimated } \\
9 \text { meters }\end{array}$ & $\begin{array}{l}\text { Good Sounding, } \\
\text { Low Noise, } \\
\text { Moderate NMR } \\
\text { Water Signal }\end{array}$ \\
\hline $\begin{array}{l}\text { 13/White } \\
\text { Sands } \\
\text { Well } 1\end{array}$ & WS-W1 & 120 & 500 & $\begin{array}{l}\text { Tularosa } \\
\text { Basin, } \\
\text { Pleistocene } \\
\text { Gypsum }\end{array}$ & $\begin{array}{l}\text { Measured } \\
0.6 \text { meters }\end{array}$ & $\begin{array}{l}\text { Poor Sounding, } \\
\text { High Noise, } \\
\text { High NMR } \\
\text { Water Signal }\end{array}$ \\
\hline $\begin{array}{l}\text { 14/White } \\
\text { Sands } \\
\text { Well } 6\end{array}$ & WS-W6 & 150 & $<150$ & $\begin{array}{l}\text { Tularosa } \\
\text { Basin, } \\
\text { Pleistocene } \\
\text { Gypsum }\end{array}$ & $\begin{array}{l}\text { Measured } \\
0.5 \text { meters }\end{array}$ & $\begin{array}{l}\text { Excellent, } \\
\text { Sounding, } \\
\text { Low Noise, } \\
\text { High NMR } \\
\text { Water Signal }\end{array}$ \\
\hline $\begin{array}{l}\text { 15/White } \\
\text { Sands } \\
\text { Dune } \\
\text { Top }\end{array}$ & WSDUNE1 & 100 & $<100$ & $\begin{array}{l}\text { Tularosa } \\
\text { Basin, } \\
\text { Pleistocene } \\
\text { Gypsum }\end{array}$ & $\begin{array}{l}\text { Estimated } \\
4 \text { meters }\end{array}$ & $\begin{array}{l}\text { Excellent } \\
\text { Sounding, } \\
\text { Low Noise, } \\
\text { High NMR } \\
\text { Water Signal } \\
\end{array}$ \\
\hline $\begin{array}{l}\text { 16/Eagle } \\
\text { Ranch } \\
\text { Alama- } \\
\text { gordo }\end{array}$ & $\begin{array}{l}\text { ALAMO } \\
\text { and } \\
\text { ALAMO2 }\end{array}$ & 20 & 1000 & $\begin{array}{l}\text { Tularosa } \\
\text { Basin, } \\
\text { Pleistocene } \\
\text { Gypsum }\end{array}$ & $\begin{array}{c}\text { Greater } \\
\text { Than } \\
50 \text { meters }\end{array}$ & $\begin{array}{l}\text { Excellent } \\
\text { Sounding, } \\
\text { Low Noise, } \\
\text { High NMR } \\
\text { Water Signal } \\
\end{array}$ \\
\hline
\end{tabular}




\begin{tabular}{|c|c|c|c|c|c|c|}
\hline \multicolumn{7}{|c|}{$\begin{array}{c}\text { Table 6-2 (cont.) } \\
\text { NEW MEXICO SITES }\end{array}$} \\
\hline $\begin{array}{l}\text { Site No. } \\
\text { \& Name } \\
\text { (See } \\
\text { Fig. 6-2) }\end{array}$ & Sounding & $\begin{array}{c}\text { Ave. } \\
\text { Peak } \\
\text { Signal } \\
\text { (nV) }\end{array}$ & $\begin{array}{c}\text { Ave. } \\
\text { Noise } \\
(\mathrm{nV})\end{array}$ & $\begin{array}{l}\text { Physio- } \\
\text { graphic } \\
\text { Area/ } \\
\text { Geology }\end{array}$ & $\begin{array}{c}\text { GW } \\
\text { Depth } \\
(\mathbf{m})\end{array}$ & Comments \\
\hline $\begin{array}{l}\text { 17/Farm- } \\
\text { ington, } \\
\text { Morton } \\
\text { Well } 2\end{array}$ & MORT2 & $<10$ & 100 & $\begin{array}{l}\text { San Juan } \\
\text { Basin, } \\
\text { Cretaceous } \\
\text { Sandstones, } \\
\text { Shales, and } \\
\text { Limestones }\end{array}$ & $\begin{array}{c}\text { Estimated } \\
\text { Greater } \\
\text { Than } 30 \\
\text { meters }\end{array}$ & $\begin{array}{l}\text { Fair Sounding, } \\
\text { Low Noise, } \\
\text { Low NMR } \\
\text { Water Signal }\end{array}$ \\
\hline $\begin{array}{l}\text { 18/Farm- } \\
\text { ington, } \\
\text { Choke- } \\
\text { cherry } \\
\text { Canyon }\end{array}$ & CHOKET1 & $<50 ? ?$ & $>10,000$ & $\begin{array}{l}\text { San Juan } \\
\text { Basin, } \\
\text { Cretaceous } \\
\text { Sandstones, } \\
\text { Shales, and } \\
\text { Limestones }\end{array}$ & $\begin{array}{c}\text { Estimated } \\
\text { Greater } \\
\text { Than } 15 \\
\text { meters }\end{array}$ & $\begin{array}{l}\text { Poor Sounding, } \\
\text { Extremely High } \\
\text { Noise, Cannot } \\
\text { Determine } \\
\text { NMR Water } \\
\text { Signal }\end{array}$ \\
\hline $\begin{array}{l}\text { 19/Farm- } \\
\text { ington, } \\
\text { La Plata } \\
\text { River }\end{array}$ & FARM1 & $100 ? ? ?$ & $>1,000$ & $\begin{array}{l}\text { San Juan } \\
\text { Basin, } \\
\text { Cretaceous } \\
\text { Sandstones, } \\
\text { Shales, and } \\
\text { Limestones }\end{array}$ & $\begin{array}{c}\text { Estimated } \\
\text { Greater } \\
\text { Than } 15 \\
\text { meters }\end{array}$ & $\begin{array}{l}\text { Poor Sounding, } \\
\text { High Noise, } \\
\text { Cannot } \\
\text { Determine } \\
\text { NMR Water } \\
\text { Signal }\end{array}$ \\
\hline $\begin{array}{c}\text { 20/Farm- } \\
\text { ington, } \\
\text { McGee } \\
\text { Park }\end{array}$ & FARM2 & $100 ? ? ?$ & $>500$ & $\begin{array}{l}\text { San Juan } \\
\text { Basin, } \\
\text { Tertiary } \\
\text { Sandstones, } \\
\text { and Shales }\end{array}$ & $\begin{array}{l}\text { Estimated } \\
\text { Less } \\
\text { Than } 2 \\
\text { meters }\end{array}$ & $\begin{array}{l}\text { Poor Sounding, } \\
\text { High Noise, } \\
\text { Cannot } \\
\text { Determine NMR } \\
\text { Water Signal }\end{array}$ \\
\hline
\end{tabular}

Historical geology dictates the type of source rock available for redistribution by the forces of erosion and fluvial deposition. Knowledge of the depositional environment of an area gives a good indication of its mineralogy and the types of sediment found downstream. The source rock of the field sites surveyed in New Mexico range from Paleozoic carbonates to Tertiary volcanics. Most of them are located in unconsolidated Cenozoic deposits and groundwater was close to the surface. Four different hydrogeologic settings were selected around New Mexico: the San Juan Basin, the Rio Grande Valley, the Tularosa Basin, and the Pecos River Valley (Figure 6-2). 


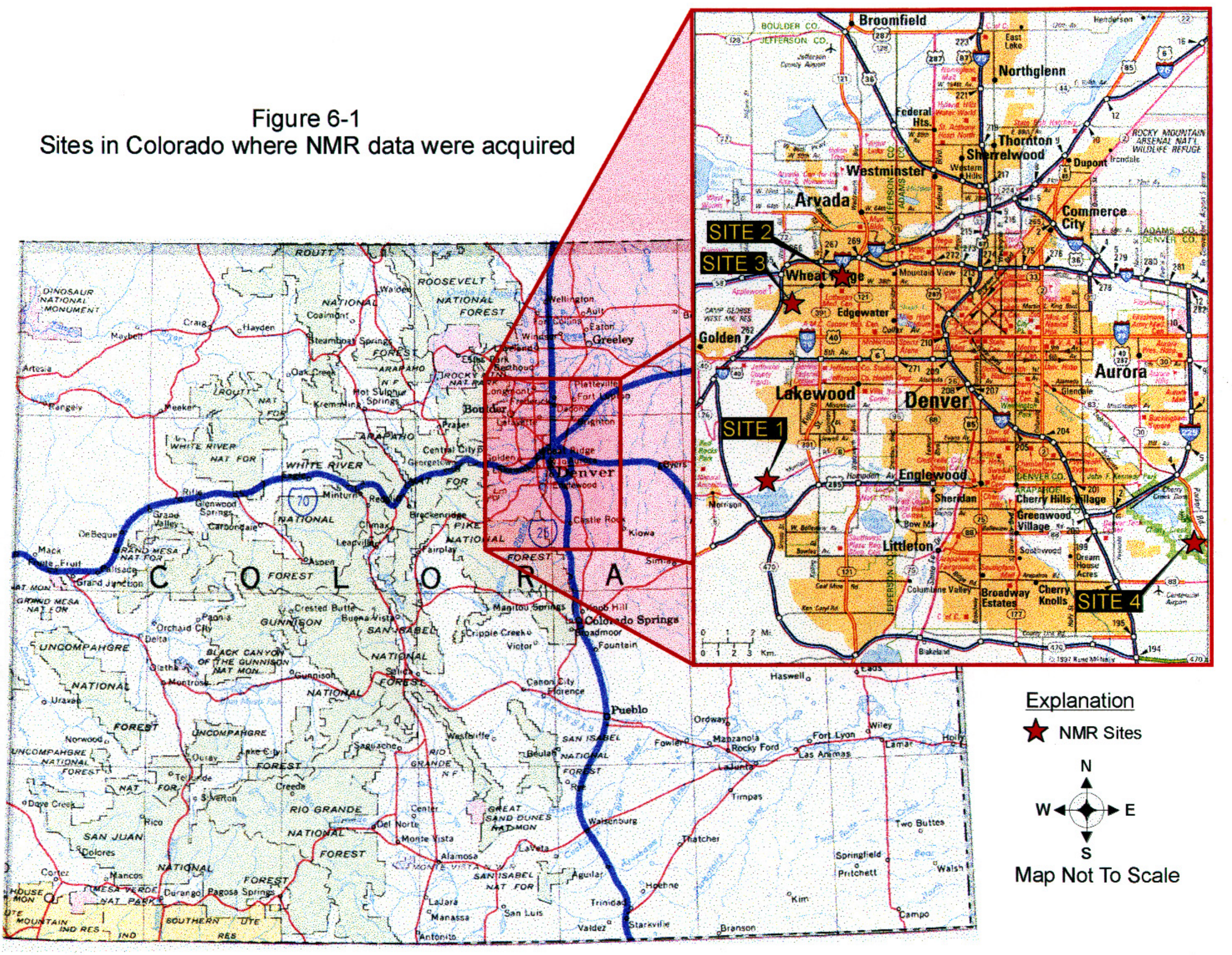


Figure 6-2

Sites in New Mexico where NMR data were acquired

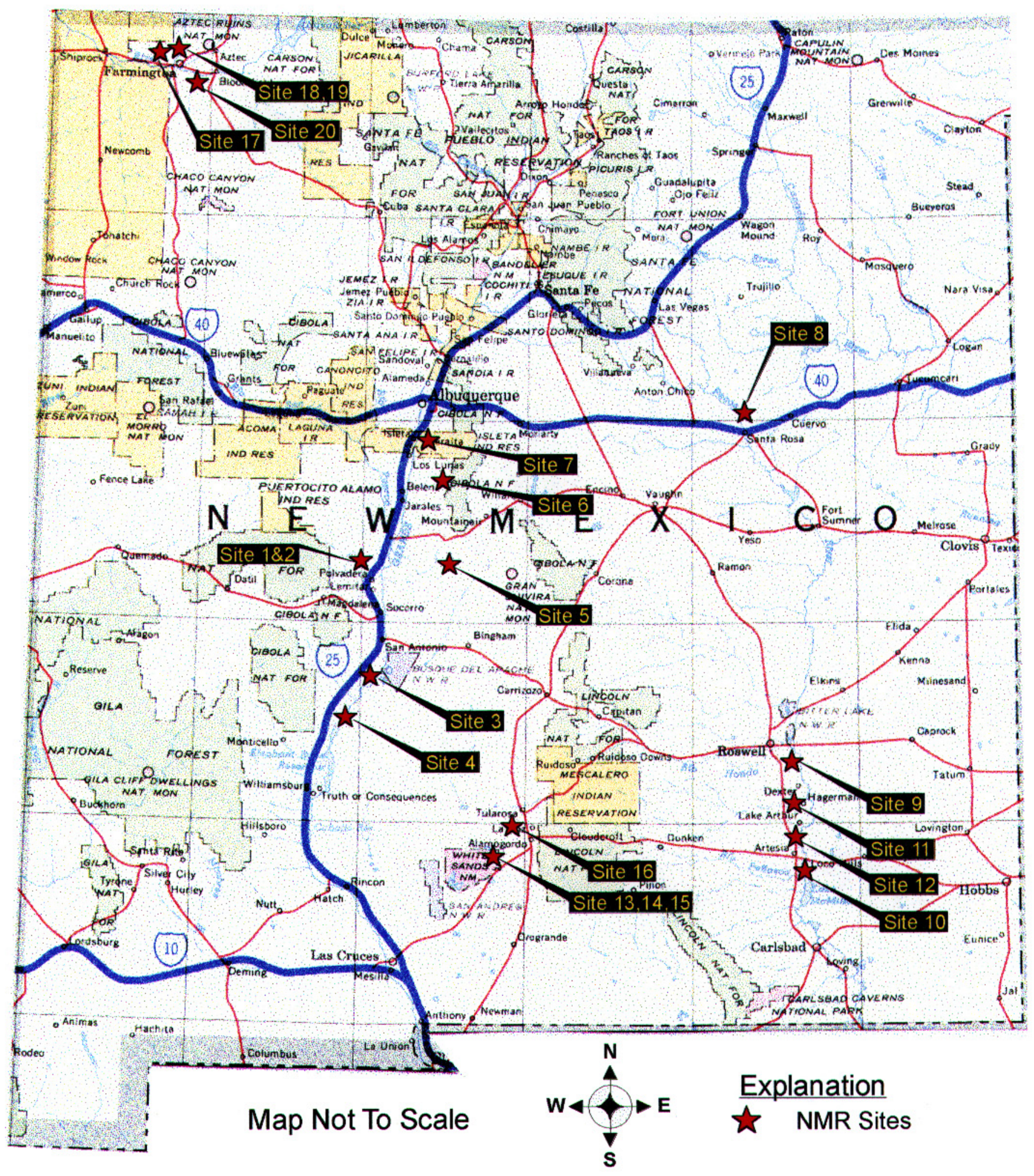




\section{RESULTS AND DISCUSSION}

Tables 6-1 and 6-2 summarize the NMR measurements taken in Colorado and New Mexico during the course of this investigation. Measurements were made at sites with varying geologic conditions. As a result, an understanding was obtained of the parameters of a soil- water system that influence the NMR signal. The major parameters influencing the NMR signal were found to be:

-Surface-to-volume ratio, and grain and pore size distribution (clay content).

- Presence of paramagnetic ions and ferromagnetic minerals in the water and soil.

\subsection{Colorado Sites}

\subsubsection{The Denver Basin}

Measurements were made at four sites (Table 6-1) in the Denver Basin, Bear Creek, Prospect Park, Cherry Creek, and Clear Creek. At one site, Clear Creek ambient electromagnetic noise precluded recording data. Figure 7-1 is a composite graph of the data acquired at Bear Creek, Prospect Park, and one typical station from Cherry Creek. The top part of the figure is the signal recorded at different pulse moments (Q's), and the bottom half of the figure is the inversion of the data in terms of water content versus depth. The data shows low signal at Bear Creek and Prospect Park, and high signal at Cherry Creek. The dominant soil type at Bear Creek and Prospect Park is clays, and the water table at both sites is within $5 \mathrm{~m}$ from the surface. Volumetric water contents, as would be determined by weighing and drying, can be expected to be between $20 \%$ to $35 \%$ at these two sites. The reason for the low signal and corresponding low apparent water content is illustrated by Figure 3-9. The relaxation time of protons of water in clays is expected to be considerably shorter than the 30 milliseconds delay time between termination of the pulse in the transmitter and the onset of data acquisition in the receiver. Most of the signal at Bear Creek and Prospect Park will have decayed before onset of data acquisition, and extrapolation of the signal to zero time is not feasible.

At Well MH3 in Cherry Creek, a series of NMR measurements were made over a three month period. To calibrate equipment and to determine reproducibility of NMR data, acquisition, and inversion. The repeat measurements are shown in Figure 7-2. The conclusion from the' data is that the behavior of the NMR signal is repeatable over time, but the absolute magnitude of the signal, particularly at large Q's, varies significantly. The Cherry Creek site is located in a stream channel eroded in the Denver Formation and shows a good NMR signal and corresponding high water content. It was, therefore, decided to make measurements in Cherry Creek in detail along two cross-sections. The measurements at Cherry Creek are the most detailed made under this program.

Cherry Creek: The sites at Cherry Creek traverse channels eroded in the Denver Formation and infilled with coarse grained sediments. Nearby Cherry Creek has changed course over time and measurements were likely made over old stream channels. A location map of the measurements is shown on Figure 7-3. Measurements were made along two cross-sections, A-A' and B-B'. Crosssection B-B' traverses the present location of Cherry Creek, cross-section A-A' traverses abandoned and infilled stream channels. The eroded channels have been infilled with sands and gravels. Outside the erosion channels, the sediments overlaying bedrock are silts and clays, and the sandstone and shales of the Denver Formation occur near the surface. The data acquired at Cherry Creek was the most complete data acquired under the DOE contract, and below the results are discussed in 
some detail. Along both cross-sections at Cherry Creek, NMR measurements were made with $50 \mathrm{~m}$ diameter figure eight transmitter loops and time domain electromagnetic (TDEM) measurements with $30 \mathrm{~m}$ by $30 \mathrm{~m}$ square transmitter loops. From TDEM measurements, the geoelectric section (lateral and vertical variation in electrical) is derived. Although there were several nearby power lines, the measured NMR water signal was sufficiently strong at this site that reasonable data was nonetheless obtained.

The results of the NMR measurements along the two cross-sections are given in Figures 7-4 and 7-5, where water content cross-sections derived from inversion of NMR recordings are shown. Superimposed on the color maps are the water content profiles as a function of depth at each station. The water content profiles along B-B' are also shown superimposed on the hydrogeologic information in Figure 7-6. The water content profiles superimposed on the hydrogeologic data in Figure 7-6 can best be used to explain the NMR results. Outside the channel, eroded in the Denver Formation (stations \#20 and \#14), low water contents are contents inferred from the low amplitude of the NMR signal measured. The relaxation time of the protons of water in silts and clays is expected to be short, less than 30 milliseconds, so that the signal will have largely decayed by the onset of data collection in the NUMIS instrument. The actual volumetric water content, that would be obtained by weighing and drying samples, likely is as high as $25 \%$. Only at stations in the channel (e.g. stations \#16 and \#17), where coarse grained soils are found, do the NMR measurements show high water content. In these coarse grained soils, large pore sizes are expected to occur, and a fraction of the protons associated with water in the large pores will have longer relaxation times, resulting in recording a higher amplitude NMR signal.

The color contours of electrical resistivity for the geoelectric sections shown along A-A' and B-B' are also given in Figures 7-4 and 7-5. These resistivity contours can best be interpreted with the help of Figure 7-7, which shows characteristic ranges of resistivity for different soil types. Sands and gravels have high values of resistivity and clays display low resistivities. The geoelectric sections derived from TDEM along A-A' and B-B' show the highest resistivities along the same part of the section as where high water contents are inferred from NMR data. The depth of occurrence of the high resistivities is interpreted somewhat deeper than the high water contents derived form NMR. Outside the channel the resistivities measured with the TDEM are about 10 to $15 \mathrm{ohm}-\mathrm{m}$ indicative of fine grained soils.

Thus, the NMR and TDEM in this setting provides confirming information, high water contents are inferred from NMR measurements in the sands and gravels infilling the channel; the geoelectric section derived from TDEM display high resistivities, characteristic of sands and gravels at the same locations. The ground water at Cherry Creek has a low concentration of dissolved solids, and resistivities are mainly determined by soil types. In settings with high concentration of dissolved solids, NMR and TDEM can provide complimentary data. The geoelectric section derived from TDEM data will be highly influenced by dissolved solids (ground water quality) and NMR data may indicate the presence of aquifers (saturated zones of coarse grained sediments).

The water content profiles derived from the inversion of the NMR data show a sharp decrease in water content below a depth of $10 \mathrm{~m}$. This is unrealistic. It is more likely that the real water content remains about $20 \%$. The reason for the decrease is likely the short relaxation times of the protons in water in silts and clays below the sand and gravel layer. Table 7-1 lists the decay times derived from the NUMIS inversion program, and these data support the decrease in relaxation time with depth as the cause of the lower derived water contents with depth. 


\begin{tabular}{|c|c|}
\hline \multicolumn{3}{|c|}{ Table 7-1 } \\
Relaxation Times at Different Values of Pulse-Moment $(Q)$ \\
Computed from NMR Data obtained at Cherry Creek, Station \#7 \\
(Question marks indicate pulse moments for which the signal \\
quality was too poor to reliably determine the relaxation time)
\end{tabular}

\subsection{New Mexico Sites}

\subsubsection{The Rio Grande Valley}

The NMR measurements made at four sites in the Rio Grande Valley are shown in the composite graphs on Figure 7-8. The top half of the figure displays the NMR signal measured at different pulsemoments (Q's). All measurements were made with $50 \mathrm{~m}$ diameter figure eight transmitter loops. The sites were selected at locations with dominantly coarse grained sediments near surface and with high water tables. Water contents on the order of $10 \%$ to $25 \%$ are expected at each site. The scale of the signal strength has been expanded to show the differences between the sites. The reason for the low NMR signal is likely due to the presence of magnetite in soils. The presence of magnetite was confirmed by the collection of particles on a magnet, however the percentage of magnetite was not determined. Magnetite is a ferromagnetic mineral and has a high induced magnetization and will rapidly de-phase proton spins of water molecules in its vicinity. The presence of magnetite is expected to greatly shorten relaxation time of protons of water molecules. The source of magnetite in the soils of the Rio Grande Valley likely is the extensive volcanic activity on the Colorado Plateau and the Basin and Range which are the origin of the sediments in the Rio Grande Valley.

The measurements in the Rio Grande Valley appear to place a major limitation on the application of NMR measurements for water content. The results illustrate that soil parameters other than pore size distribution and water content influence. the NMR measurement with the NUMIS instrument. An important advantage foreseen for NMR was the unique relation between liquid water, pore size, and NMR signal, a relation that would require little or no calibration. Water content in the soils of the Rio Grande Valley can not be measured, because the presence of magnetite has shortened the relaxation time. By the onset of recording in the NUMIS instrument, most of the signal will have decayed, and water content must be inferred by extrapolating the signal to zero time. Extrapolation to zero time is not feasible if most of the signal has decayed.

Unfortunately, magnetite is a common mineral worldwide. The three most common minerals present in the Earth's crust are (in order) silica, alumina, and oxides of iron. Iron makes up about $5 \%$ of the Earth's crust by weight and is responsible for most of the yellows, browns, reds, and greens we see at the surface of the Earth (Desautels 1968). The most commonly found iron ores are hematite $\left(\mathrm{Fe}_{2} \mathrm{O}_{3}\right)$ and magnetite $\left(\mathrm{Fe}_{3} \mathrm{O}_{4}\right)$. Magnetite is formed by metamorphosis of hematite and is commonly found as an intrusion into limestone (skarn). Large deposits of magnetite occur in 
the eastern United States, Sweden, and Norway. All of the most frequently encountered iron ores, however, are common accessory minerals to igneous rock, especially granite and quartz. Areas downstream from any magmatic source rock would likely contain transported eroded sediments with a magnetic signature. Since igneous rocks, in small to large assemblages, occur in almost all regions of the world, there is virtually no place where magnetite could not occur. In fact, it is so common in near surface rocks and deposits that creating a map of magnetite presence would be a very large task.

Alluvial sediments with a magnetite presence can, over sufficient time, become cleansed of the ore. Grains and nodules of magnetite will eventually wash out through the action of a river, and the magnetic signature will become depleted. Consequently, a good place to look for magnetite-free sediments is in a paleo river system (e.g. Cherry Creek). Also, any sedimentary formation with a small igneous source constituent will have little or no magnetic signature. An old, clean, sandstone formation from the Paleozoic era also can be expected to have low residual magnetite. Conversely, if sampling is performed in geologically young areas or those with a large igneous source component, a much higher magnetite presence can be expected.

Of the four physiographic areas surveyed in New Mexico in the present study, two are located in basins with little to no igneous source rock. The Tularosa Basin and the Pecos River Valley derive their sediments from carbonate-based evaporites and soils, thus, have little to no magnetite presence. The San Juan Basin sediments have a mixture of igneous and non-igneous source rock. The Rio Grande Valley, however, derives much of its sediment from volcanic source rock; therefore, a high magnetite presence is expected.

\subsubsection{The Pecos River Valley}

The NMR measurements made at four sites in the Pecos River Valley are shown in the composite graph on Figure 7-9. The top half of the figure shows the NMR signal measured at different pulse moments (Q's), and the bottom half displays the water content profiles derived from inversion of the NMR data. The site selection approach was similar to the approach used in the Rio Grande Valley. Sites were selected in dominantly coarse grained sediments with high water tables. At all sites in the Pecos River Valley, NMR signals with significant amplitude were recorded, and the inversion of the NMR data in terms of water content profiles show corresponding higher water contents than measured in the Rio Grande River Valley.

The reason for the difference in NMR signals measured between sites in the Rio Grande Valley and Pecos River Valley is expected to be due to the presence of a significant percentage of magnetite in the soils in the Rio Grande Valley and much lower percentage of magnetite in the Pecos River Valley. The sediments filling the Pecos River Valley are mainly derived from sandstones, limestones, and anhydrites. Table 7-2 lists the relaxation times at the various $Q$ 's for the NMR soundings at Lea Lake. The relaxation times are longer than the delay time between transmitter turn off and onset of data collection. This is the reason significant NMR signal is recorded.

The water content profiles inverted from the NMR measurements deviate from the hydrogeologic knowledge about the water content profiles. For example, consider the curves measured at the Lea Lake site. Both the NMR signal as a function of $Q$ and the water content profile inverted from the NMR show high values from about the surface to a depth of $15 \mathrm{~m}$. It is not realistic to expect water contents less than $5 \%$ below $15 \mathrm{~m}$. The reason for this behavior is presently not understood. The most likely explanation is that relaxation times for the protons in ground water are shortened with depth. Supporting evidence for this explanation is found in the geoelectric section derived from a TDEM sounding at this site. The geoelectric section in Figure 7-10 shows a relatively low value of resistivity to depth of $40 \mathrm{~m}$, likely indicating ground water of high TDS. If paramagnetic 
ions are part of the impurities in the water, relaxation times could be significantly shortened. This explanation is also supported by the data on relaxation times shown in Table 7-2. The accuracy of determining relaxation times decreases with decreasing signal. The trend nevertheless is consistent for several sites.

\begin{tabular}{|c|c|c|}
\hline \multicolumn{3}{|c|}{ Table 7-2 } \\
Relaxation Times at Different Values of Pulse-Moment (Q) \\
Computed from NMR Data Taken at Lea Lake, New Mexico \\
\hline$Q$ (A-ms) & Signal (nV) & Relaxation Time (ms) \\
\hline 122 & 381 & 343.2 \\
\hline 149 & 410 & 352 \\
\hline 168 & 426 & 296 \\
\hline 209 & 463 & 268 \\
\hline 251 & 468 & 239 \\
\hline 298 & 461 & 236 \\
\hline 350 & 449 & 244 \\
\hline 413 & 431 & 253 \\
\hline 486 & 407 & 242 \\
\hline 577 & 363 & 147 \\
\hline 668 & 316 & 57 \\
\hline 787 & 257 & 61 \\
\hline 930 & 213 & 77 \\
\hline 1063 & 174 & 91 \\
\hline 1245 & 142 & 103 \\
\hline 1455 & 131 & 124 \\
\hline
\end{tabular}

\subsubsection{The Tulrosa Basin}

The NMR measurements at three sites in the Tularosa Basin are given on the composite graph of Figure 7-11. The top half of the figure shows the NMR signal recorded at different $Q$ 's, and the bottom half shows the water content profiles inverted from the NMR data. All three sites have in common a high NMR signal at low $Q$ 's (near surface) and a rapid decrease in NMR signal at $Q$ 's above 1000 A-ms. The water content profiles obtained by inversion from the NMR signals mirror this behavior. The water contents are high in the upper $10 \mathrm{~m}$ and fall off rapidly to very low (less than 3\%) before increasing again. This behavior is not consistent with hydrogeologic information. The water table at this site is within $5 \mathrm{~m}$ from the surface and is expected to remain at values above $25 \%$ with depth.

Again the best explanation between NMR derived water content profiles and reality likely must be found in shortening of relaxation times of protons of water with depth. The cause of the shortened relaxation times again is expected to be an increase in concentration of paramagnetic ions. Supporting evidence for this postulation are the decrease in relaxation times with increasing $Q$ determined from the data and tabulated in Table 7-3 and the geoelectric section derived from the TDEM sounding on Figure 7-12. The geoelectric section shows resistivity values of less than 1 $\Omega$-mfrom about 10 to 40 meters depth, which in sands would be indicative of relatively high TDS. These low resistivity values also imply that the inversion routine included in the NUMIS instrument, which does not account properly for subsurface conductivity (see Appendix B for details), will not give trustworthy results. 


\begin{tabular}{|c|c|c|}
\hline \multicolumn{3}{|c|}{$\begin{array}{c}\text { Table 7-3 } \\
\text { Relaxation Times at Different Values of Pulse-Moment }(Q) \\
\text { Computed from NMR Data taken at White Sands, Well } 6 \\
\text { (Question marks indicate pulse moments for which the signal } \\
\text { quality was too poor to reliably determine the relaxation time) }\end{array}$} \\
\hline$Q$ (A-ms) & Signal (nV) & Relaxation Time (ms) \\
\hline 164 & 303 & 93 \\
\hline 205 & 301 & 238 \\
\hline 227 & 299 & 245 \\
\hline 264 & 289 & 256 \\
\hline 337 & 251 & 257 \\
\hline 405 & 218 & 220 \\
\hline 469 & 182 & 30 \\
\hline 582 & 132 & $?$ \\
\hline 646 & 116 & $?$ \\
\hline 790 & 91 & $?$ \\
\hline 898 & 60 & $?$ \\
\hline 1037 & 65 & $?$ \\
\hline 1212 & 49 & $?$ \\
\hline
\end{tabular}

\subsubsection{The San Juan Basin}

NMR measurements were made at four sites in the San Juan Basin near Farmington. Ambient electromagnetic noise precluded recording NMR data at two sites. The results at Morton Well \#2 are shown on Figure 7-13. The figure is the NMR signal recorded at different values of $Q$. The NMR signal recorded at all $Q$ values is low, indicative of low water content. This site has a deep vadose zone with a water table depth greater than $50 \mathrm{~m}$. 

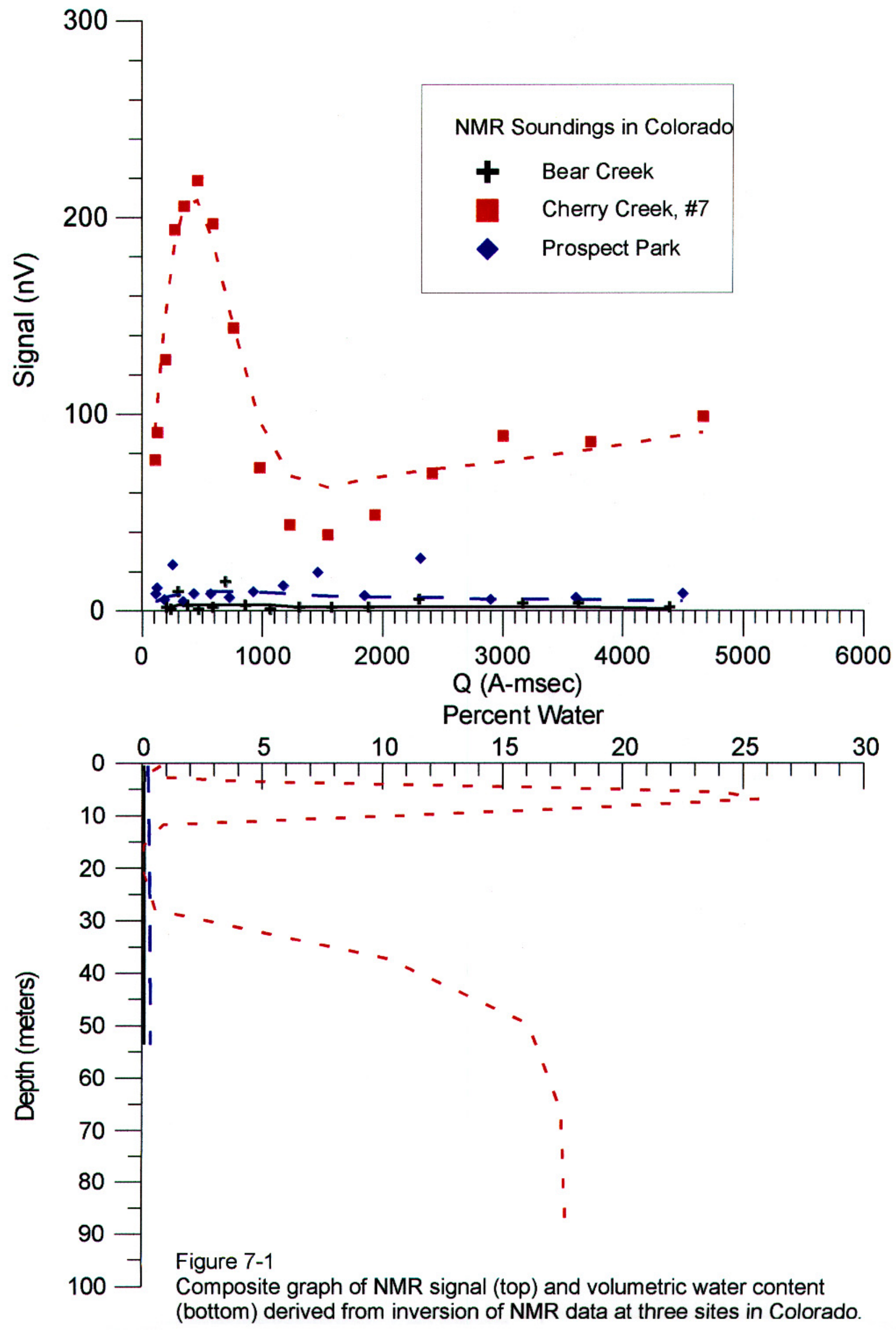


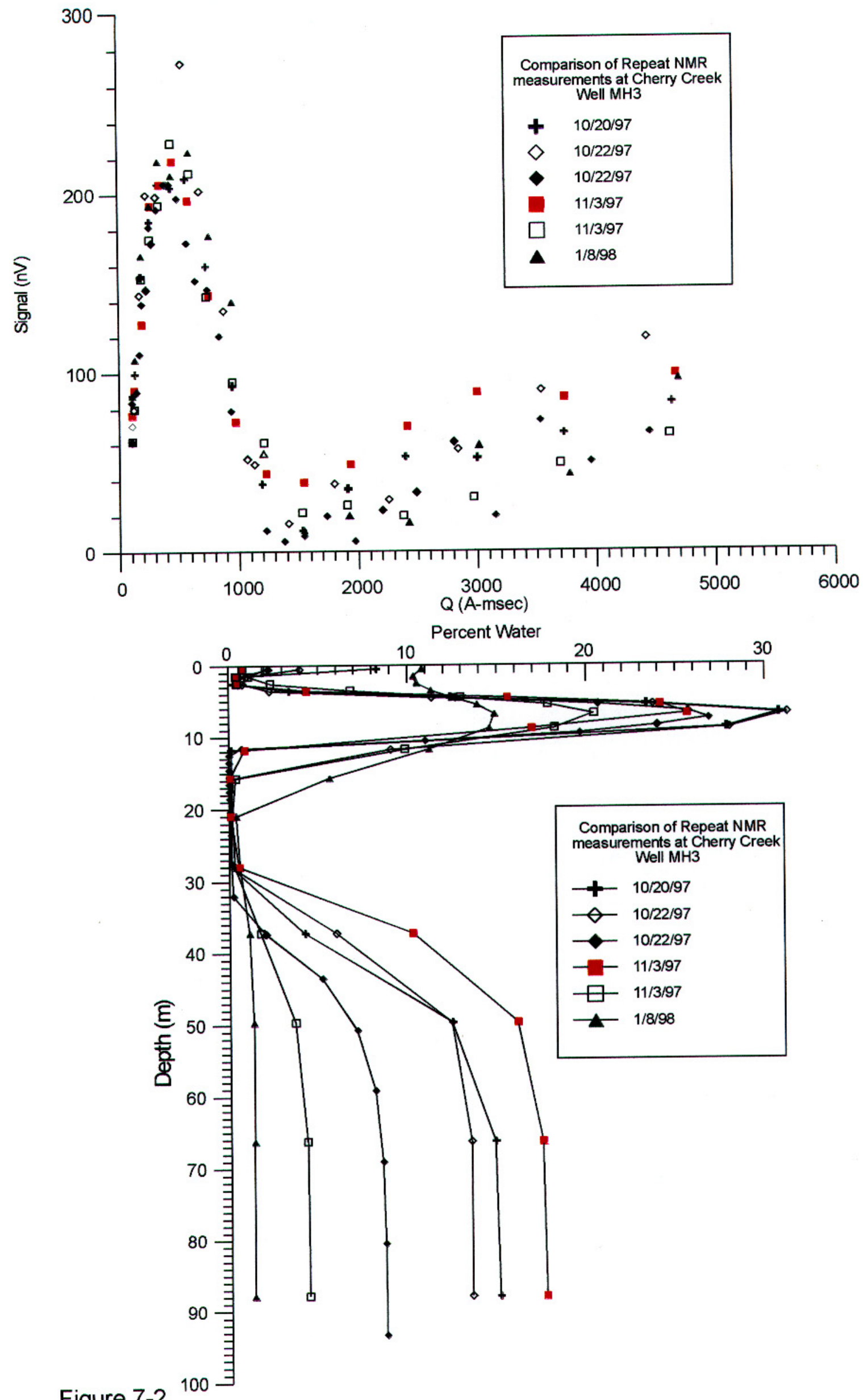

Figure 7-2

Composite graph of repeat measurements at well MH3 at Cherry Creek, Colorado. NMR response (top), inversion in terms of water content (bottom). 

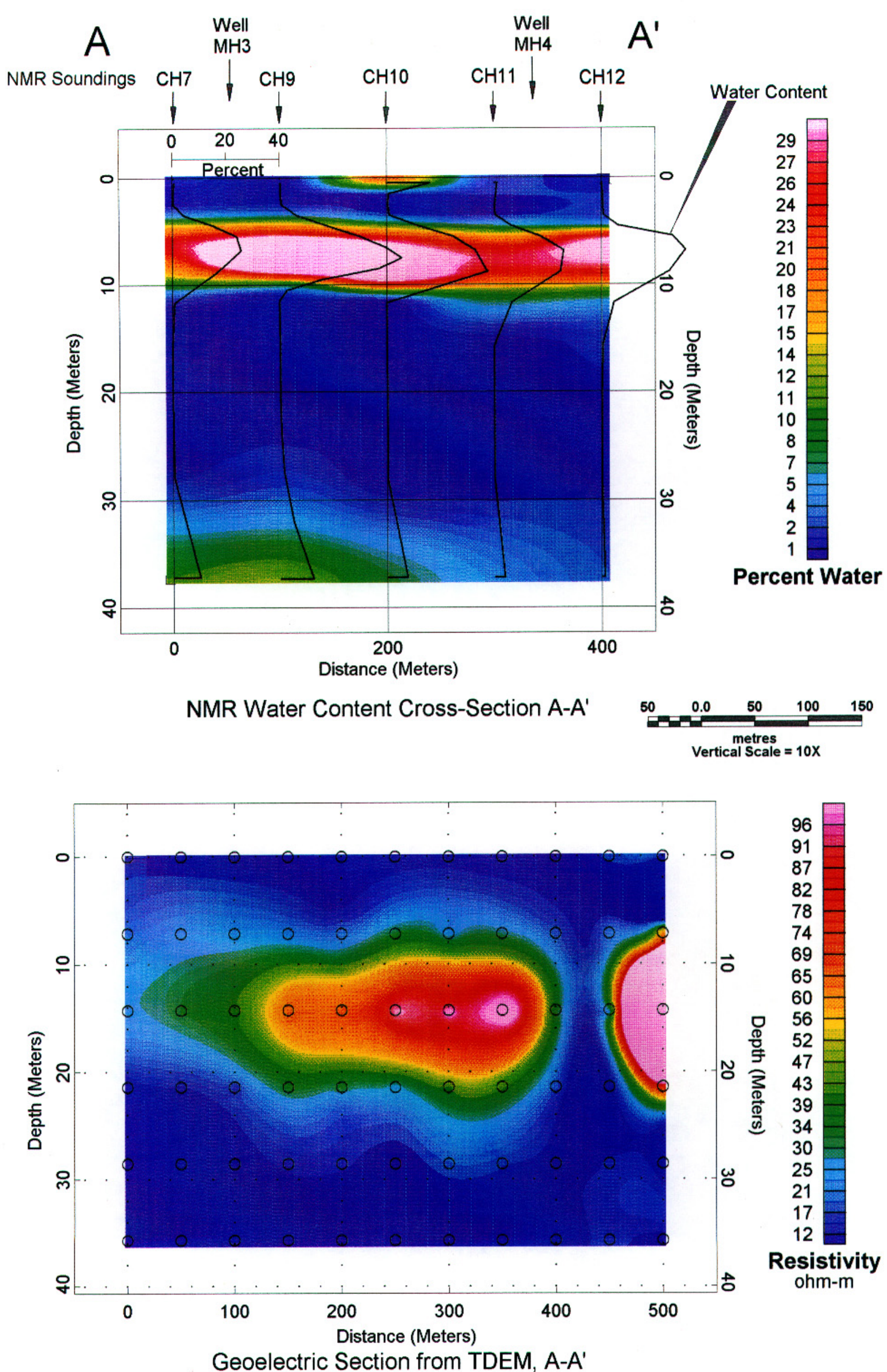

Figure 7-4

Inversion of NMR data in terms of water content (top), and geoelectric section derived from inversion of TDEM data along cross-section A-A' at Cherry Creek, Colorado 

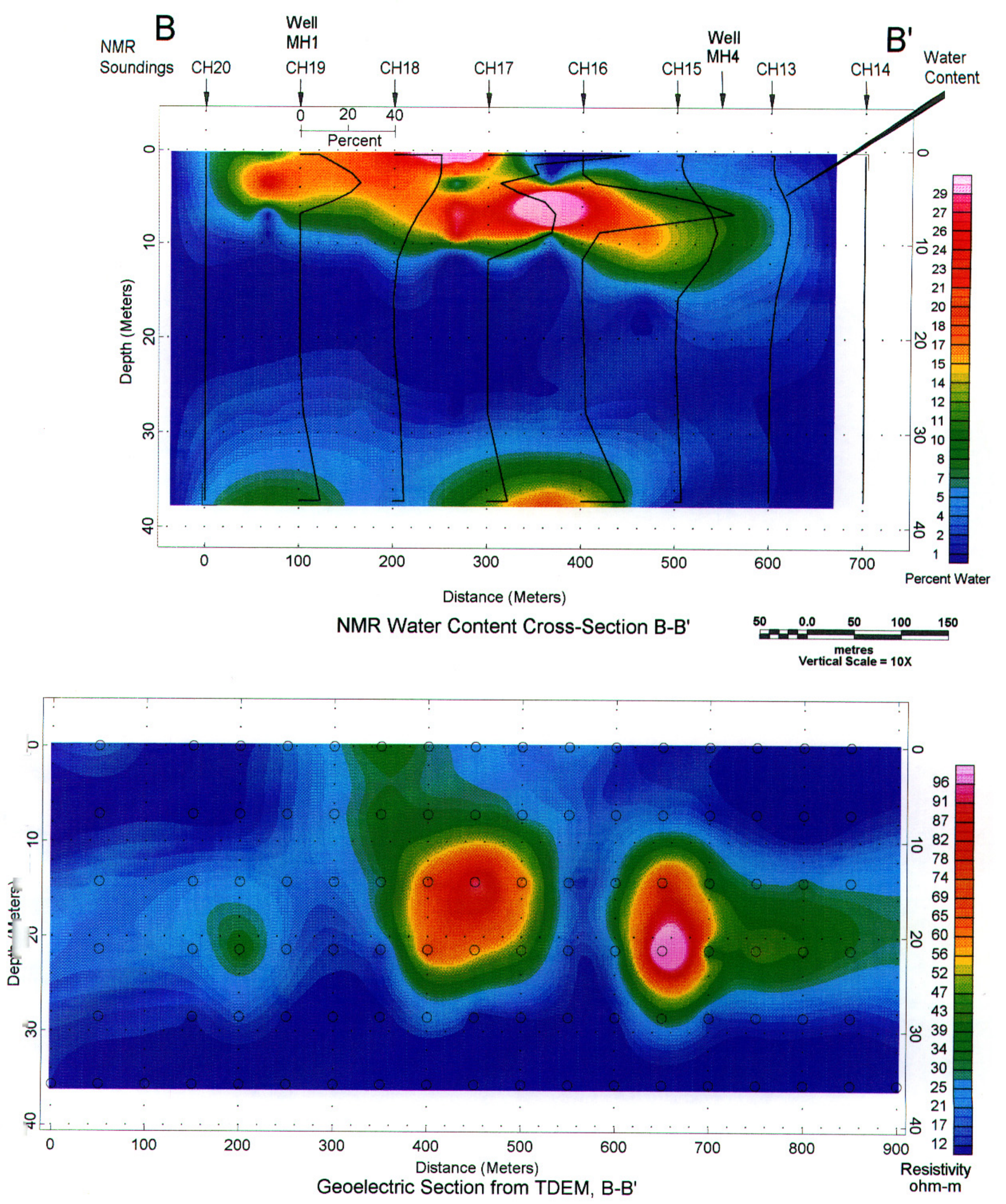

Figure 7-5

Inversion of NMR data in terms of water content (top), and geoelectric section derived from inversion of TDEM data along cross-section B-B' at Cherry Creek, Colorado 


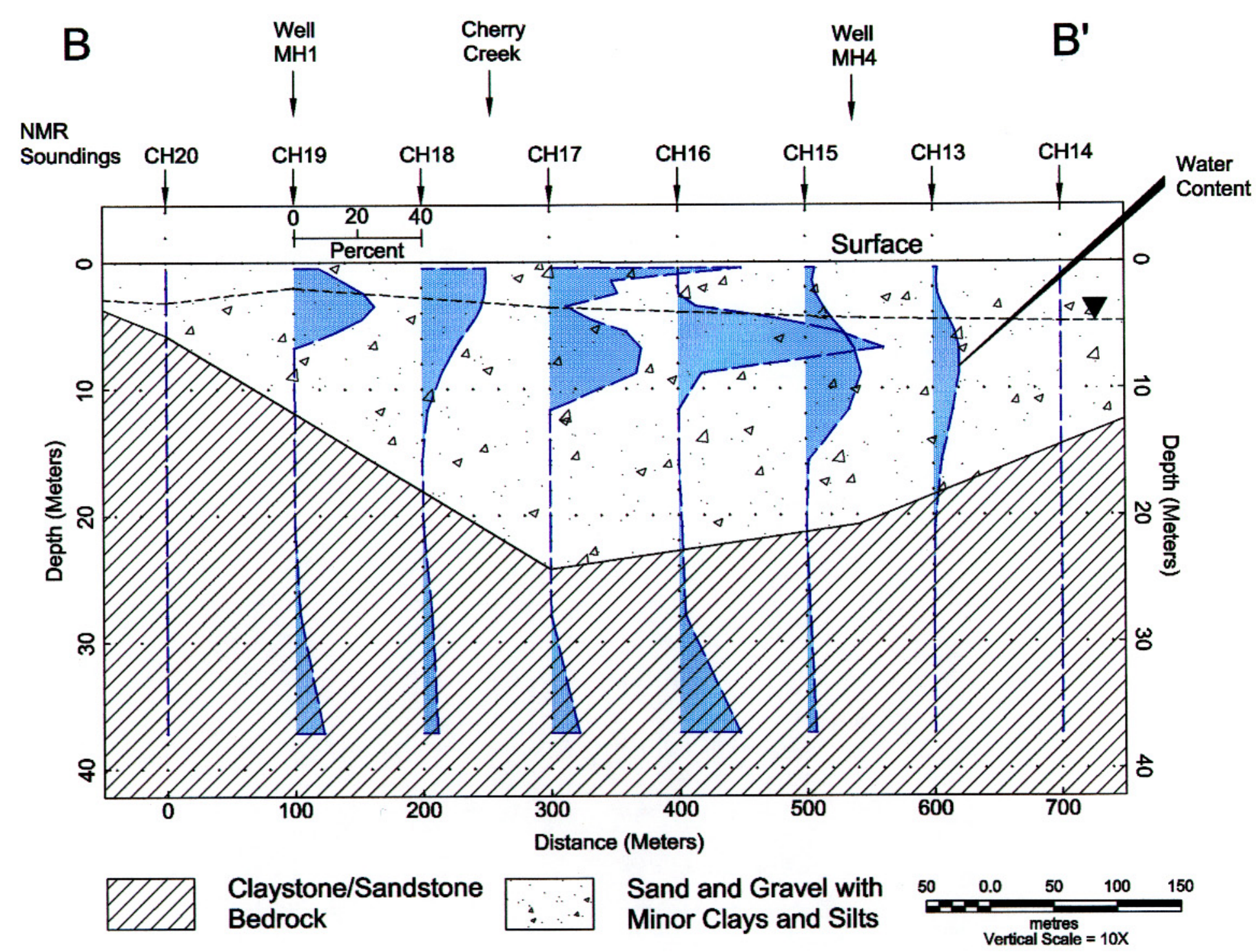

Figure 7-6

Water content profiles derived from inversion of NMR data superimposed on hydrogeologic section B-B' from Cherry Creek, Colorado 


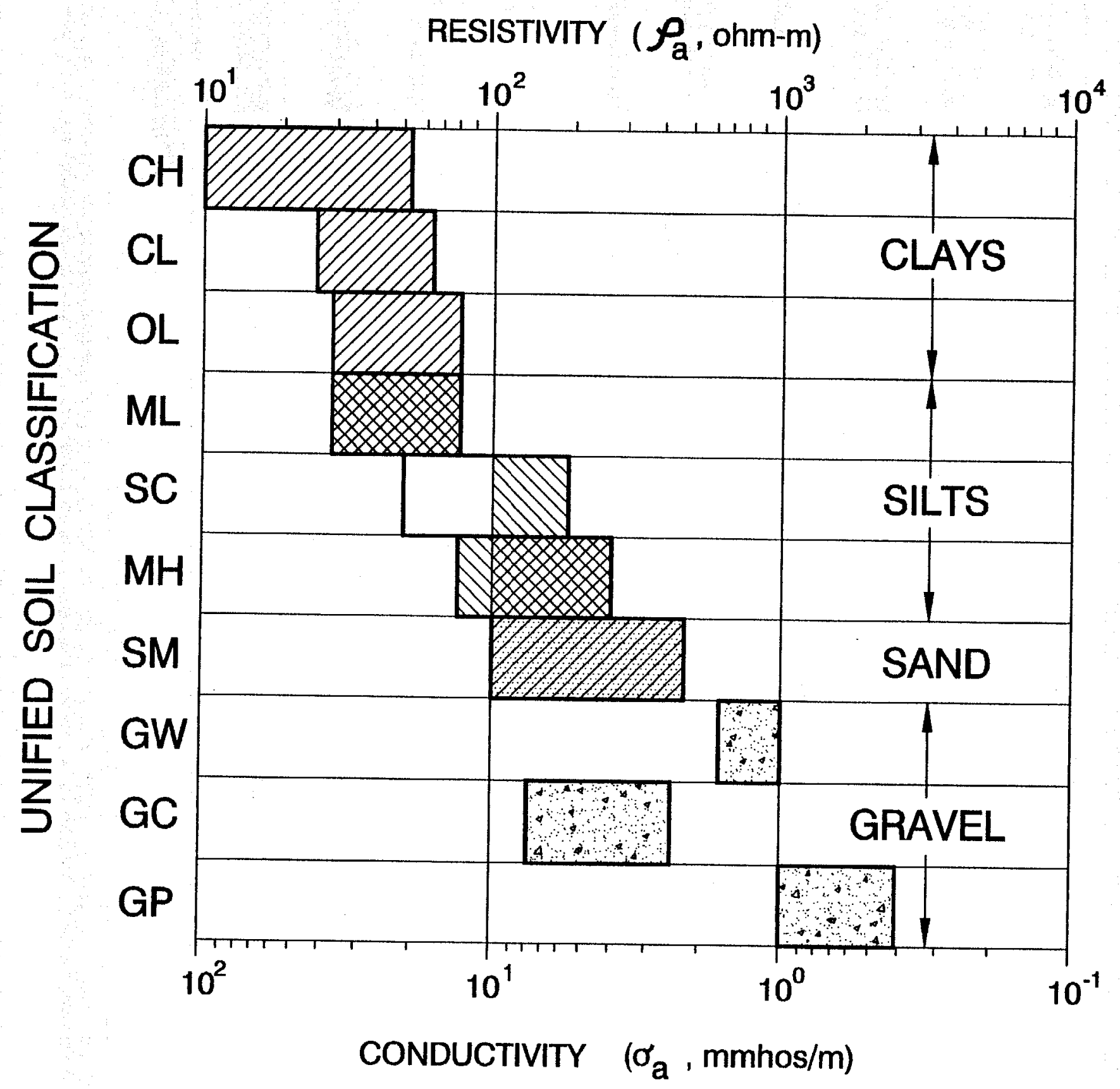

Figure 7-7

Relationship between soil types and resistivity. 

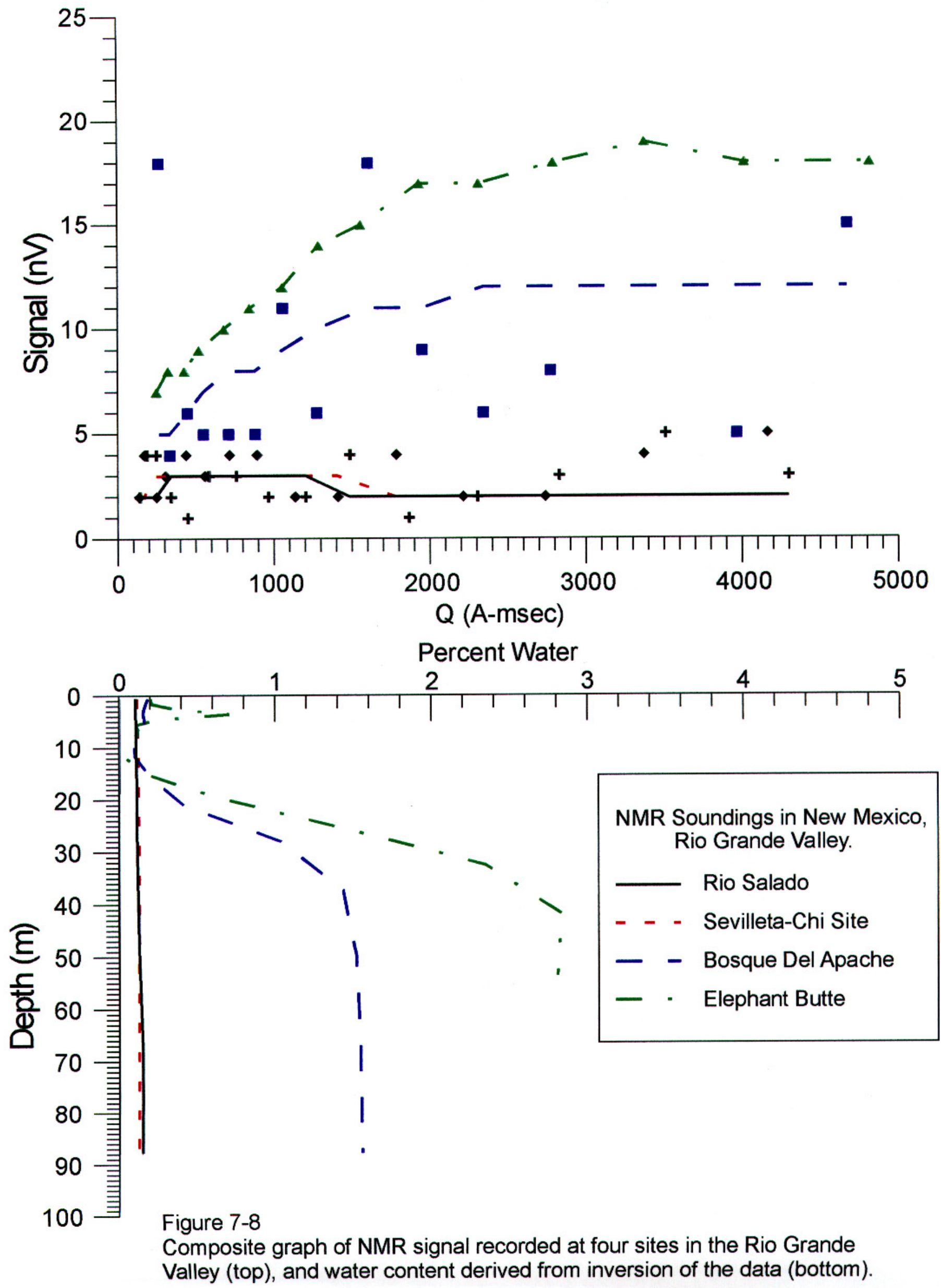

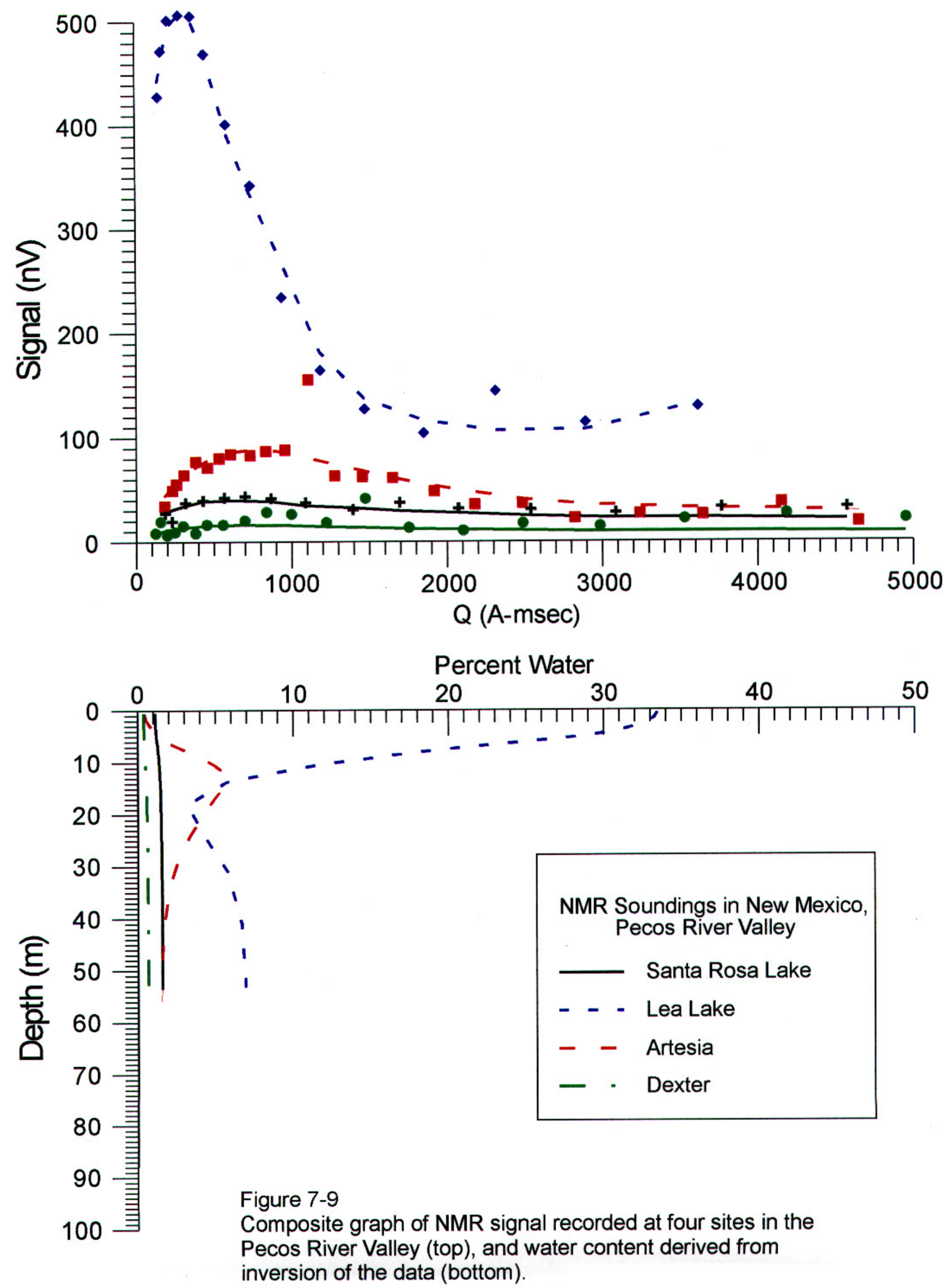


\section{LEALAKE}
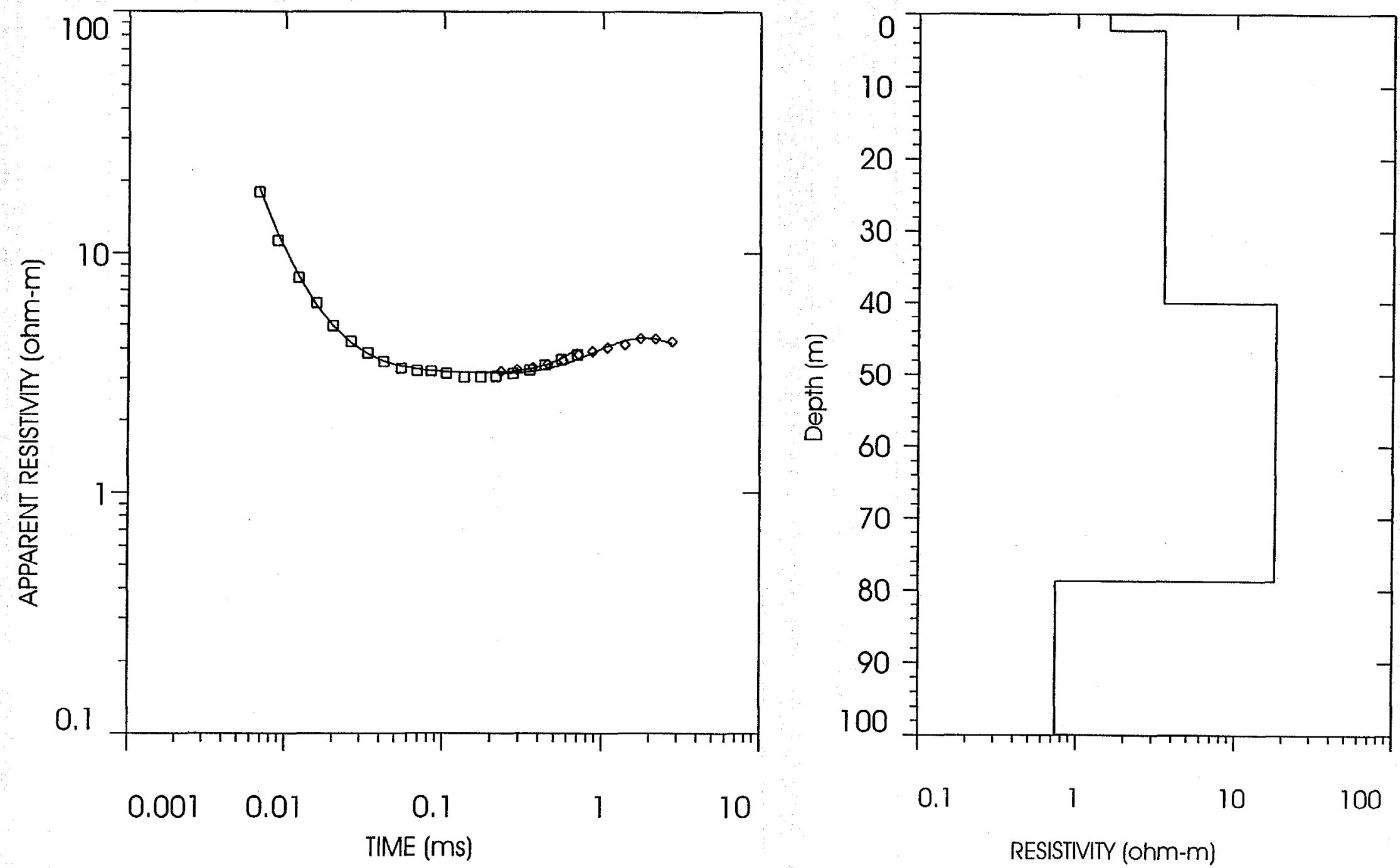

Figure 7-10

Apparent resistivity curve (left) and geoelectric profile (right) derived from inversion of TDEM data (shown on left) at Lea Lake Site. 

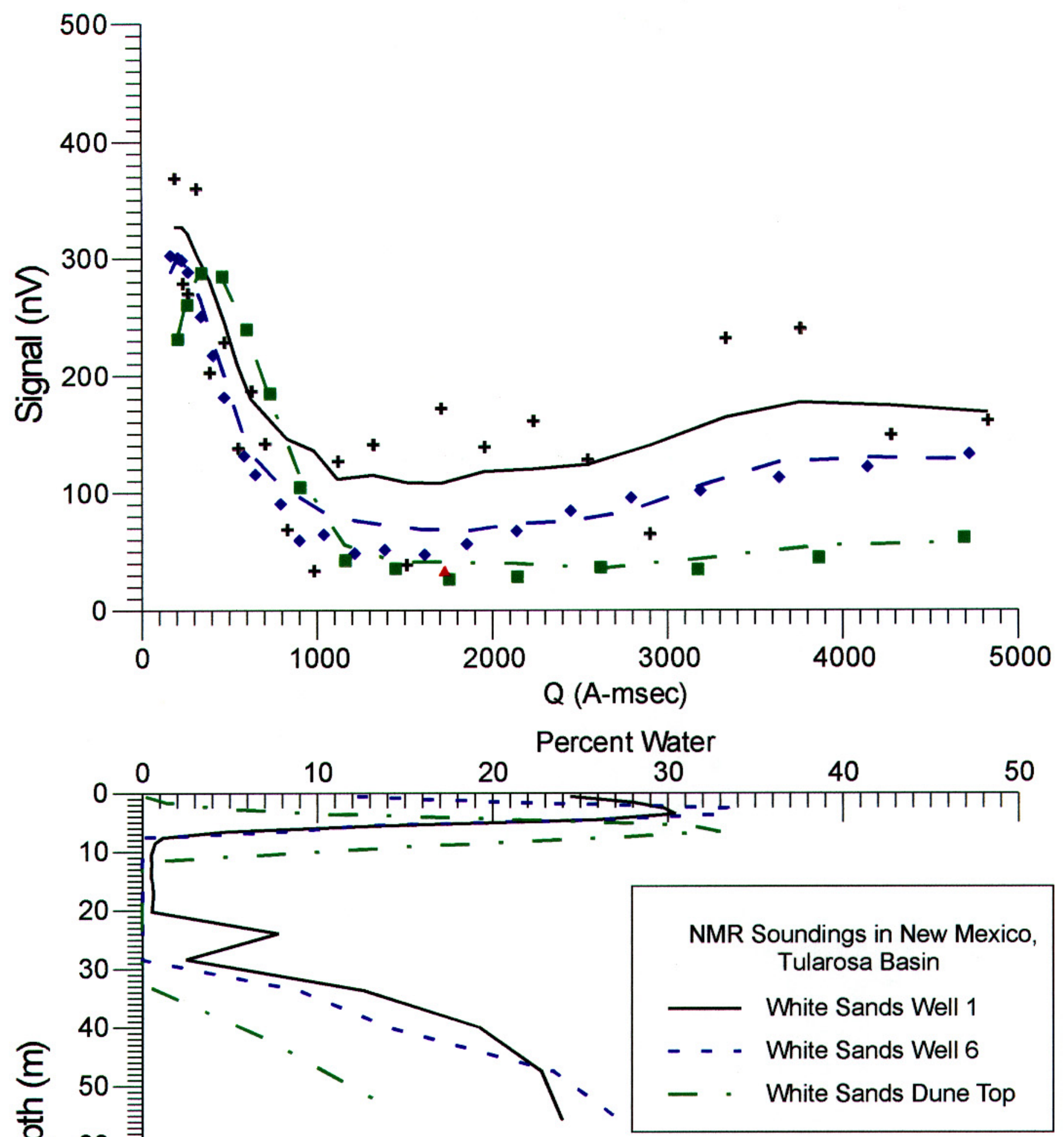

Figure 7-11

Composite graph of NMR signal recorded at three sites in the Tularosa Basin (top), and water content derived from inversion of the data (bottom). 

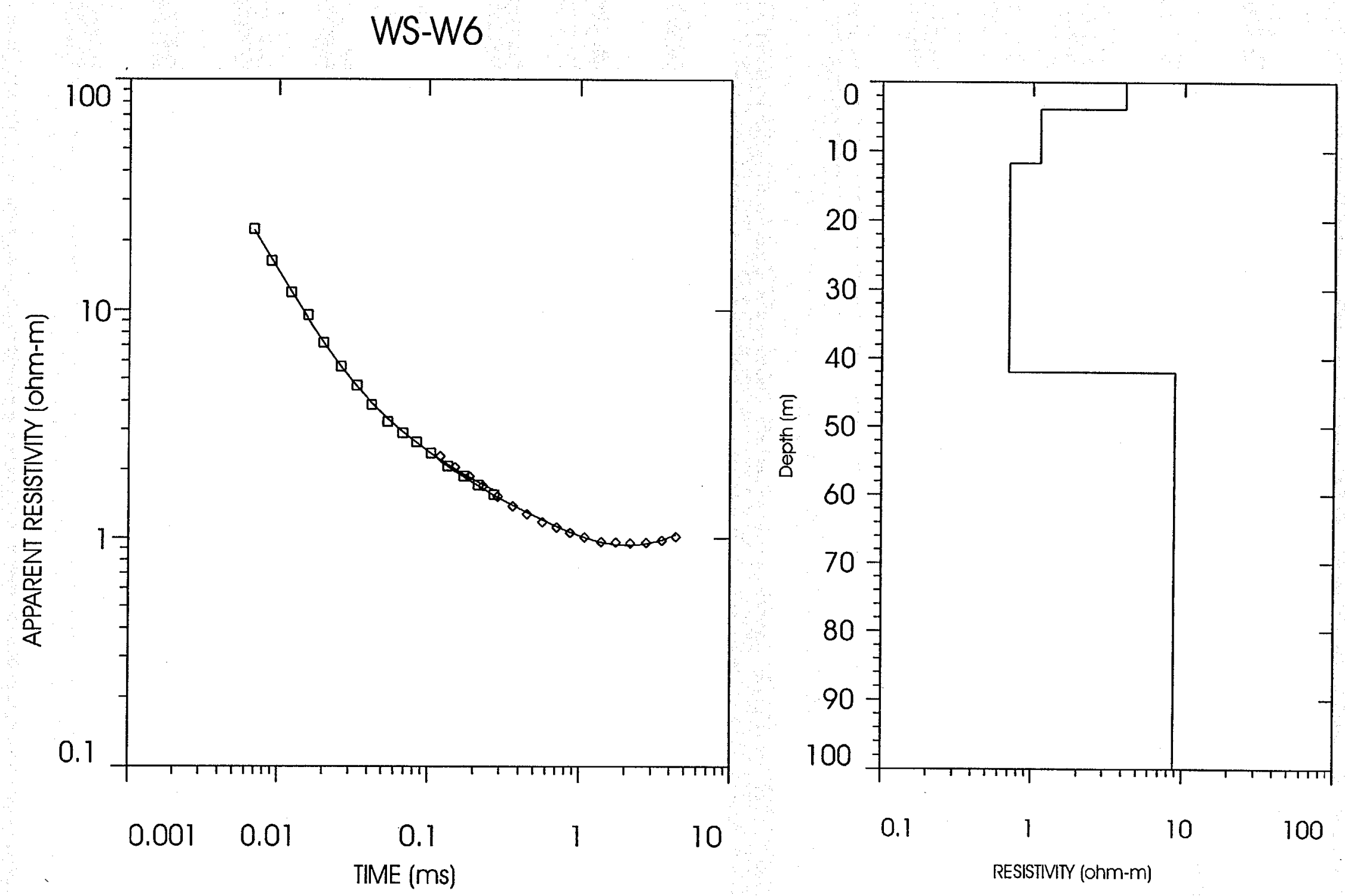

Figure 7-12

Apparent resistivity curve (left) and geoelectric profile (right) derived from inversion of TDEM data (shown on left) at White Sands, Well 6. 


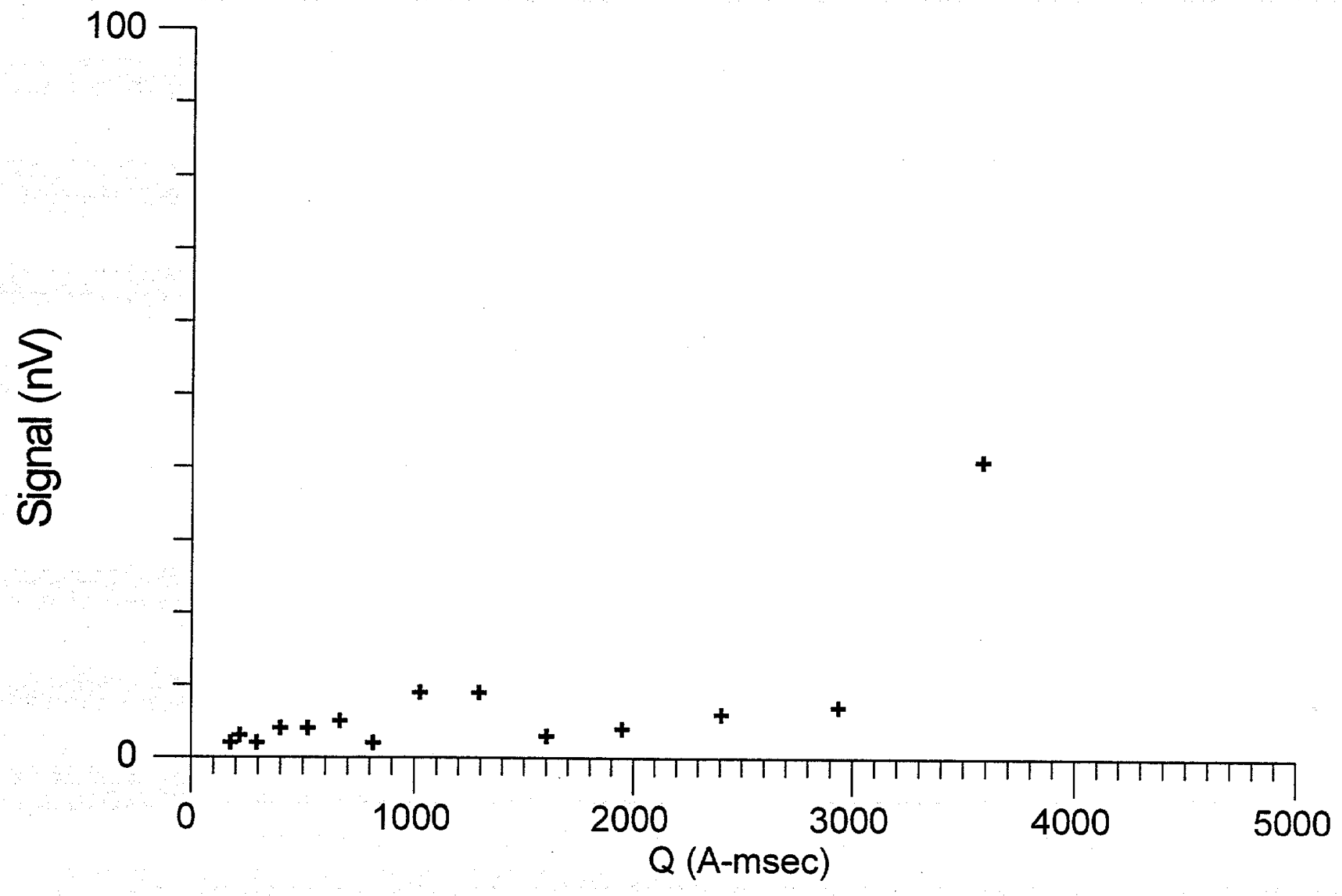

Figure 7-13

The NMR signal recorded near Farmington, New Mexico on the Colorado Plateau in the San Juan Basin (Morton Well \#2) 


\section{CONCLUSIONS}

Surface nuclear magnetic resonance imaging was performed at approximately twenty locations in Colorado and New Mexico at sites with different hydrogeologic settings. The instrument used for the measurements was the NUMIS instrument manufactured by the IRIS Instruments Company of Prance. The design of this instrument is based on the "Hydroscope" equipment developed and tested by Russian investigators at the Laboratory of Combustion and Chemical Engineering in Novosibirsk, Russia. Two important objectives can potentially be addressed with surface NMR imaging. These are:

- Determining water content distribution. The NMR signal uniquely relates to protons in water molecules if the geolectric section is known from other measurements.

- Estimating pore size distribution from which an estimate of hydraulic permeability can be obtained.

The conclusions from the measurements at the various sites can be summarized as follows:

- In surface NMR measurements, a low amplitude signal (tens to hundreds of nanovolts) must be recorded. Recording reliable data is, therefore, often not feasible at sites with high ambient electromagnetic noise. The main source of noise are power lines, and it has often not been possible to record reliable data within 1 to $2 \mathrm{~km}$ from power lines. An effective procedure to mitigate noise is to employ figure eight transmitter loops rather than circular loops. Use of figure eight loops was found to decrease noise by a factor of ten or greater. All measurements reported were recorded with figure eight loops. A disadvantage of figure eight loops compared to circular loops is that effective exploration depths are reduced by about one-half. The NMR signal is proportional to the static magnetic field that aligns a small fraction of the magnetic moment of the protons. In surface NMR, that static field is the Earth's magnetic field, which can not be altered. Other procedures for improving signal to noise, such as stacking and signal processing, are extensively employed in the NUMIS instrument. The extent to which further improvements can be made is subject to further investigation.

-Perhaps the greatest limitations of the technology are the many factors of a soil-water system influencing relaxation times of protons of water molecules. The NMR signal measures the decaying signal of the perturbed proton spins returning to equilibrium along the Earth's magnetic field. The time over which the signal decays to 1/e (about 37\%) of its instantaneous value is called the relaxation time. This relaxation time is influenced by pore size distribution, surface-to-volume ratio, paramagnetic ions dissolved in the ground water, and the presence of ferromagnetic minerals. In any NMR instrument, there is a delay time between the termination of the pulse in the transmitter and the onset of recording during transmitter off time. In the NUMIS instrument, that delay time is $30 \mathrm{~ms}$. Water content is derived from the instantaneous signal, i.e., signal at zero time. To obtain the signal at zero time the measurements recorded starting at $30 \mathrm{~ms}$ must be extrapolated back to zero time. Clearly, in situations where the protons in water (or a fraction of the protons) have relaxation times comparable to or less than $30 \mathrm{~ms}$, the extrapolation to zero time is highly inaccurate. At a number of sites with magnetite minerals, the relaxation time of protons in water was shortened to the extent that no NMR signal was recorded with the NUMIS instrument, although the water content of the soils is expected to be $25 \%$ or greater. 
It is probable that the limitation caused by the large delay time in the NUMIS instrument can be corrected and improved, so that more accurate water content distributions can be derived from NMR measurements. However, the fact that several factors besides pore size distribution, such as ferromagnetic minerals and paramagnetic ions, influence the NMR relaxation time may make derivation of pore size distributions difficult.

The results of measurements at sites throughout Colorado and New Mexico indicate that surface NMR measurements are not yet a viable technology for hydrologic investigations. The application of the technology is highly site specific. For this technology to become practical, several advances need to be made. They are:

- Shortening the instrument delay time, so that water in smaller pores and in soils with higher concentrations of dissolved magnetic impurities can be detected. This will involve both improvements in the internal electronics of the NUMIS instrument, and reduction in the intrinsic ringing time of the transmitter loop. Such advances will also aid the development of a full understanding of the factors of a soil-water system that influences the relaxation time distribution. This understanding is gradually being developed via measurements by several investigators under controlled laboratory conditions.

- Improving noise suppression, so that the instrument can be used in less benign electromagnetic environments. The aim would also be to allow the use of gasoline generators in place of car batteries and capacitors as the current source. The larger driving voltages obtainable from a generator would allow the use of less bulky transmitter loop cables, and would speed up the measurement process itself. The use of figure eight loops is one step in this direction, but is not sufficient.

In the oil and gas industry, the NMR log is becoming an increasingly important tool to derive reservoir permeability. Perhaps at this time it is fruitful to explore to what extent a NMR borehole tool can be used to derive in-situ hydraulic permeability and water content in the vadose zone and shallow aquifers. 


\section{REFERENCES}

[1] Andreyev, S. V. and Martens, B. K., 1960, Soil moisture determination by the method of nuclear magnetic resonance, Soviet Soil Sci. 10, 1129-1132.

[2] Allen, J. E. and Kottlowski, F. E., 1967, Bottomless Lakes side trip, Scenic trips to the geologic past, No. 3, New Mexico Bureau of Mines and Mineral Resources, New Mexico Institute of Mining and Technology, Socorro, New Mexico.

[3] Allmendinger, R. J., 1971, Hydrologic control over origin of gypsum at Lake Lucero, White Sands National Monument, New Mexico, Master's thesis, New Mexico Institute of Mining and Technology, Socorro, New Mexico.

[4] Anderholm, S. K., 1987, Hydrology of the Socorro and La Jencia Basins, Socorro County, New Mexico, U.S. Geological Survey Water-Resources Investigations Report 84-4342, Albuquerque, New Mexico.

[5] Baars, D. L., 1983, The Colorado Plateau, a geological history, University of New Mexico Press, Albuquerque, New Mexico.

[6] Cabezas, Pascal, 1991, The southern Rocky Mountains in west-central New Mexico- Laramide structures and their impact on the Rio Grande rift extension, New Mexico Geology 13, No. 2.

[7] Chen, Chia-Shyun, Holmes, C., Li, W., Chace, D., Fort, M., He, J., and Liu, J., 1993, Determination of three-dimensional aquifer anisotropy of an unconfined aquifer under partially penetrating pumping conditions, New Mexico Water Resources Research Institute Report No. 279. New Mexico State University, Las Cruces, New Mexico.

[8] Desautels, P. E., 1968 The Mineral Kingdom (Madison Square Press, New York).

[9] Fenneman, N. M., 1931, Physiography of the Western United States, (McGraw-Hill, New York).

[10] Freese, R. A., and Cherry, J. A., 1979, Groundwater (Prentice Hall).

[11] Gev, I., Goldman, M., Rabinovich, B., Rabinovich, M., Issaa, A., 1996, Detection of the water level in fractures phreatic aquifers using nuclear magnetic resonance (NMR) geophysical measurements, J. Applied Geophysics 34, 227-282.

[12] Goldman, M., Rabinovich, B., Rabinovich, M., Gilad, D., Gev, I., and Schirov, M., 1994, Application of the integrated NMR-TDEM method in ground water exploration in Israel, J. of Applied Geophysics 31, 27-52.

[13] Hendrickson, G. E. and Jones, R. S., 1952, Geology and groundwater resources of Eddy County, New Mexico, Groundwater Report No. 3, New Mexico Bureau of Mines and Mineral Resources, Socorro, New Mexico.

[14] Herndrickx, J. M. H., 1990, Determination of hydraulic soil properties, in Process studies in hillslope hydrology, Chapter 3, pp. 42-93, M.G. Anderson and T.P. Burt editors (John Wiley and Sons). 
[15] Hendrickx, J. M. H., Khan, S., Bannink, M. H., Birch, D., and Kidd, C., 1991, Numerical analysis of groundwater recharge through stony soils using limited data, J. of Hydrology 127, 173-192.

[16] Hinedi, Z. R., Kabala, Z. J., Skaggs, T. H., Borchardt, D. B., Lee, R. W. K., and Chang, A. C., 1993, Probing soil and aquifer material porosity with nuclear magnetic resonance, Water Resour. Res. 29 3861-3866.

[17] Hinedi, Z. R., Chang, A. C., Anderson, M. A., and Borchardt, D. B., 1997, Quantification of microporosity by nuclear magnetic resonance relaxation of water imbibed in porous media,

Water Resour. Res. 33 2697-2704.

[18] Kachanoski, R. G., Gregorich, E. G., and Van Wesenbeeck, I. J., 1988, Estimating spatial variations of soil water content using noncontacting electromagnetic inductive methods, Can. J. Soil Sci. 68, 715-722.

[19] Kleinberg, R. L., Kenyon, W. E., and Mitra, P. P., 1994, Mechanisms of NMR relaxation of fluids in rock, J. of Magnetic Resonance, Series A 108, 206-214.

[20] Lieblich, D. A., Legenchenko, A., Haeni, F. R., Portseian, A., 1994, Surface nuclear magnetic resonance experiments to detect subsurface water at Haddam Meadows, Connecticut, in Proc. Symposium on the Application of Geophysics to Engineering and Environmental Problems (SAGEEP), 717-729.

[21] Paetzold, R. F., De los Santos, A., and Matzkanin, G. A., 1987, Pulsed nuclear magnetic resonance instrument for soil-water content measurement: sensor configurations, Soil Sci. Soc. Am. J. 51, 287-290.

[22] Prebble, R. E. and Currie, J. A., 1970, Soil water measurement by a low-resolution nuclear magnetic resonance technique, J. Soil Sci. 21, 272-288.

[23] Reiche, Parry, 1949, Geology of the Manzanita and North Manzano Mountains, New Mexico, Bulletin of the Geological Society of America 60, 1183-1212.

[24] Roark, D. M. and Healy, D. F., 1998, Quantification of deep percolation from two flood-irrigated alfalfa fields, Roswell Basin, New Mexico, U.S. Geological Survey Water-Resources Investigations Report 98-4096; Albuquerque, New Mexico.

[25] Semenov, A. G., 1987, NMR Hydroscope for water prospecting, Proc. Seminar on Geotomography, Indian Geophysical Union, Hyderabad, India, pp. 66-67.

[26] Semenov, A. G., Schirov, M. D., Legchenko, A. V., Burshtein, A. I,, Pusep, Ju, A., 1989, Device for measuring parameters of an underground mineral deposit, GB patent 2198540.

[27] Sheets, K. R., and Hendrickx, J. M. H., 1995, Non-invasive soil water content measurement using electromagnetic induction, Water Resources Research 31, 2401-2409.

[28] Shirov, M., Legchenko, A., and Creer, G., 1991, A new direct non-invasive ground water detection technology for Australia, Exploration Geophysics 22, 333-338.

[29] Shushakov, O. A., 1996, Groundwater NMR in conductive water, Geophysics 64, 998-1006.

[30] Stephens, D. B., 1995, Vadose zone processes, characterization, and monitoring, Daniel B. Stephens \& Associates, Albuquerque, New Mexico. 
[31] Thornburg, W. D., 1965, Regional Geomorphology of the United States (John Wiley and Sons, New York).

[32] Titus, F. B., Jr., 1963, Geology and ground-water conditions in eastern Valencia County, New Mexico, Groundwater Report 7, New Mexico Bureau of Mines and Mineral Resources, New Mexico Institute of Mining and Technology, Socorro, New Mexico.

[33] Trushkin, D. V., Shushakov, O. A., and Legchenko, A. V., 1994, The potential of a noisereducing antenna for surface NMR for groundwater surveys in the Earth's magnetic field, Geophysical Prospecting 42, 855-862.

[34] Van Genuchten, M. Th., Leij, F. J., and Lund, L. J. (Eds.), 1992. Indirect methods for estimating the hydraulic properties of unsaturated soils. Proceedings of the International Workshop on Indirect Methods for Estimating the Hydraulic Properties of Unsaturated Soils, Riverside, California, October 11-13, 1989. U.S. Salinity Laboratory, Agricultural Research Service, U.S. Department of Agriculture, Riverside, California, U.S.A., p 718

[35] Varian, R. H., 1962, Ground liquid prospecting method and apparatus, U.S. Patent 3.019.383. 


\section{A GEOLOGICAL DETAILS}

\section{A.1 The San Juan Basin (Sites 17, 18, 19, 20)}

The Colorado Plateau is a roughly circular area, which covers northwest New Mexico, northern Arizona, and much of Utah and western Colorado. During the Paleozoic era, it was repeatedly inundated by shallow seas accumulating hundreds of meters of sand, shale, and limestone deposits. These sediments covered thousands of square kilometers, including what is today the San Juan Basin, the Rio Grande Basin, and the Pecos River Valley. During periods of Paleozoic uplift, structural weak spots in the Earth's crust developed into either actively rising or subsiding areas. The San Juan Basin is one of several Colorado Plateau basins which actively subsided during periods of Paleozoic uplifts and filled with eroded sediments from the actively rising areas. The Permian period, however, was one during which the region was largely emergent. Hundreds and up to thousands of meters of eroded igneous sediments were transported from the ancestral Rocky Mountains to be deposited in the low-lying areas. Much of the eroded sediments had a large iron content and were deposited in a highly oxidizing environment. The extensive "red rocks" throughout the region are evidence of this sequence. During the Larimide Orogeny, beginning in late Cretaceous and continuing through mid-Tertiary, the same structural weaknesses were reactivated. Erosion from the rising San Juan Mountains produced more carbonate-based sediments, much of which were transported south to the San Juan Basin. Continued erosion during the Cenozoic era further dissected these deposits while depositing even more fluvial sediments (Baars 1983).

\section{A.2 The Rio Grande Valley (Sites 1, 2, 3, 4, 5, 6, and 7)}

The Rio Grande is a north-south trending river, which runs from central Colorado, through central New Mexico into Texas, where it forms the international boundary between the United States and Mexico. It passes through the Southern Rocky Mountain physiographic Province, the Colorado Plateau, and the Mexican Highlands section of the Basin and Range Province (Fenneman 1931). The river begins by draining the San Juan Mountains of Colorado, then flows along the west side of the Sangre de Cristo Mountains through the San Luis Valley, the Taos Valley, and the Espanola Basin, along the west side of the Sandia, the Manzano, and the Los Pinos Mountains through the Albuquerque Basin through the Socorro Trough, then along the west side of the Organ Mountains through the San Marcial Basin, the Engle Basin, the Palomas Basin, and the Hueco Basin of northern Mexico. The river valley is characterized by the presence of a major continental rift running from Leadville, Colorado, to El Paso, Texas. The stratigraphic column in the Rio Grande Valley is incomplete for the Paleozoic and Mesozoic eras. The earliest layered sediments, a massive gray carbonate system, are Mississippian in age and represent deposition from a continental shelf environment. The strata show that transgression/regression sequences continued throughout the remainder of the Paleozoic era. Maximum transgression likely was during late Permian when the San Andres carbonate system was deposited (Cabezas 1991). The Mesozoic era stratigraphic column is also incomplete. Late Triassic deposits portray an emergent period, but middle Cretaceous deposits again depict typical transgression/regression patterns (Cabezas 1991).

The Laramide Orogeny (uplift of the Rocky Mountains) occurred from late Paleocene through the early Eocene portions of the Cenozoic era. Volcanic activity was common from late Eocene through mid Pliocene affecting the entire Rocky Mountain Province. The Basin and Range tectonic period began in the Miocene. Extension of the Rio Grande Rift took place during two periods of the Cenozoic era, starting about 30 million years ago during middle Oligocene and again from late Miocene through late Pliocene, contemporaneously with the volcanism and Basin and Range 
tectonic events. Since the Laramide Orogeny, the region has been emergent and characterized by erosion and fluvial deposition. The Rio Grande River has continuously transported continental sediments into the basin reaching over 900 meters in depth (Cabezas 1991). Since so much of this region was covered by volcanic deposition, the transported sediments commonly contain Tertiary volcanic material as a source component.

\section{A.2.1 Isleta Lake Site (Site 7)}

Isleta Lake is part of a small recreational park on the Isleta Pueblo Reservation south of Albuquerque. The park is situated on the east side of the Rio Grande River on Quaternary alluvium. The NMR study site is 30 meters from the lake's west shore on highly disturbed, flat terrain with a mixture of Cottonwood trees and Salt Cedar. Ojuelos Springs Site on the Hubble Bench (Site 6). The Ojuelos Fault (Reiche 1949) (synonymous with the Hubble Springs Fault as described in Kelly 1977) is located along the west flank of the North Manzano Mountains and lies to the west of the Manzano Fault. The Hubble Bench, situated between these two faults, is approximately $88 \mathrm{~km}$ long running from the Tijeras Fault on the north to the Joyita Hills near Socorro to the south and ranges from 3-10 km wide. The Ojuelos Fault Zone probably formed the eastern border of the Rio Grande Rift valley during early rift formation (Kelly 1982). Although large sections of the bench no longer exist, the fault escarpment in the vicinity of the NMR survey site has a relief of more then 40 meters.

The site chosen for the survey lies on the Hubble Bench near the Ojuelos Fault escarpment in the southern portion of the North Manzano Mountains. Geologically, the Hubble Bench has a more diverse stratigraphy and structure than any other bench along the Rio Grande Rift throughout the Albuquerque and Espanola Basins (Kelly 1982). Formations ranging from Precambrian to Holocene outcrop here. In the vicinity of the NMR survey site, the bench has good exposures of Permian and Triassic beds and has several springs. The site chosen for this survey is adjacent to a spring, which drains into a stock pond. It lies on top of what appears to be a manmade Earthen bridge elevated approximately five meters above the level of the spring. It is highly disturbed and has sparse vegetation.

\section{A.2.2 Sevilleta Site (Site 2)}

This NMR survey location is the site of Chia Chen's 1992-1993 pumping study (Chen 1993). The site is about a quarter of a mile south of the Rio Salado on the west side of the Sevilleta National Wildlife Refuge. Chen described the site as having Holocene alluvial soil composed of interbedded sand, gravel, and silt. Approximately 16 meters below the current alluvial plain lay Pleistocene axial stream deposits similar to the upper soil, but with the addition of more clay (Chen 1993). Hand augering to $1.2 \mathrm{~m}$ on the day of the NMR survey did not reach groundwater.

\section{A.2.3 Rio Salado Site (Site 1)}

This site straddles the river channel and flood plain on the south side of the Rio Salado, again on the west side of the Sevilleta National Wildlife Refuge. It has characteristics very similar to the Chia Chen site, but because it is closer to the river, can be expected to have a slightly smaller depth to water table. Hand augering to $2.1 \mathrm{~m}$ on the day of the NMR survey, however, did not reach the water table. 


\section{A.2.4 Bosque de1 Apache Site (Site 3)}

This survey site is in the southern part of the Bosque de1 Apache National Wildlife Refuge. It sits in the southernmost firebreak, on level ground, adjacent to Monitoring Well No. 5. The location, until 5 years ago, was covered by a very dense growth of Salt Cedar, but has since been cleared. It has a soil texture of very fine sand layered with clayey sand. Hand augering to $3.9 \mathrm{~m}$ on the day of the NMR survey did not reach the groundwater.

\section{A.3 The Tularosa Basin (Sites 13, 14, 15, 16)}

The present-day Tularosa Basin is in the Mexican Highland section of the Basin and Range Province in southeast New Mexico (Fenneman 1931, Thornburg, W. D. 1965). Until the Laramide Uplift, it shared a geologic history with the Pecos River Valley: shallow seas had deposited hundreds of meters of carbonate-rich sediments. During the Uplift, however, the Tularosa Basin area developed into a north-south trending anticline. During the Basin and Range tectonic period which followed, block faulting of the anticline resulted in the elevation of the San Andres Mountains to the west, the Sacramento Mountains to the east, and the settling of the central blocks, thus creating horst and graben features with a bolson drainage pattern. The faulting and uplift of the horst blocks exposed gypsum-rich sediments of the Permian Yeso and San Andres Formations along the perimeter of the basin. Alluvial and colluvial sediments from the surrounding horsts began to cover the floor of the bolson. Precipitation drainage, too, carried tons of sediments from those newly uplifted mountains to the graben floor where the runoff collected to form temporary lakes. The largestof these playas, Otero, covered $1800 \mathrm{~km}^{2}$ (Allmendinger 1971).

At the end of the Pleistocene, Lake Otero began to dry up, revealing a thick layer of an evaporite, selenite, on the former lakebed. Once exposed to the surface, the selenite easily weathered to gypsum, was picked up by the prevailing southwest wind and deposited $15 \mathrm{~km}$ away as a dunal system (Allmendinger 1971). Over the last 25,000 years, the dunes grew to their present size, now the largest dunal gypsum deposit in the world. Today, a smaller lake, Lucero, remains in the Tularosa Basin, still yielding gypsum to the wind, while the dunes make up White Sands National Monument. The groundwater level throughout the Tularosa Basin is generally less than 3 meters below ground surface.

\section{A.4 White Sands National Monument}

Gypsum comprises all dune material at White Sands National Monument. The present survey sampled three locations in the dune system. Two were on interdunal flats, and one straddled the top and side of a dune. Both flat areas were wet at the time of sampling.

\section{A.5 The Pecos River Valley (Sites 8, 9, 10, 11, and 12)}

The Pecos River Valley forms the major part of the Pecos Section of the Great Plains Province (Fenneman 1931). It is a north-south trending valley in southeast New Mexico, bordered on the northwest by the Sangre de Cristo Mountains (the source of the Pecos River) and the Canadian Mesa, on the west by the Pedernal Hills, the Gallinas, Jicarilla, Capitan and Sacramento Mountains, on the south by the Guadalupe Mountains, on the east by the Llano Estacado, and opens via the north to the High Plains. The southern part of the Pecos River Valley in New Mexico is well known for its artesian water resources.

Southern New Mexico was the apparent northern limit to Pre-Carboniferous sea extensions while Mississippian, Pennsylvanian, and Cretaceous seas extended into northern New Mexico and 
beyond. Massive granite in this region is unconformably overlain by Paleozoic deposits. From the Cambrian period and onward through the Paleozoic era, repeated transgressions and regressions deposited many layers of sandstone, limestone, anhydrites, gypsum, and salt on top of the massive Precambrian granite. Uplift and subsequent erosion characterized most of the Mesozoic era, but the Cretaceous period once again saw transgression and deposition of more sediments in southern New Mexico (including the Chalk Bluff Formation which characterizes the Llano Estacado). During the general uplift associated with the Laramide Orogeny (late Cretaceous through Eocene), the Sangre de Cristo Mountains emerged by igneous intrusion, folding, and faulting.

The Sangre de Cristo and the Sacramento ranges contain the highest elevations of all the mountains bordering the Pecos River Valley. They contribute the largest volumes of water and sediment to the Pecos River. As part of the Rocky Mountains, much of the Sangre de Cristos are composed of Precambrian granite. Paleozoic sedimentation from the Mississippian and Pennsylvanian periods, however, was abundant and these rocks remain as surface deposits over significant areas of the Sangre de Cristos. The uplift and subsequent erosion during the Laramide Orogeny and continued erosion throughout the Cenozoic Era transported much Paleozoic sediment downstream covering the floor of the Pecos River Valley.

The Sacramento Mountains and their highest peak, Sierra Blanca, are part of the Sacramento section of the Mexican Highlands section of the Basin and Range Province (Fenneman 1931). Their sediments (including the San Andres Formation) were deposited during the Permian period, then uplifted by Tertiary faulting and volcanic activity during the Basin and Range tectonic period (middle Tertiary). The upthrown blocks form the highlands of the Sacramento Mountains. These mostly-carbonate systems crop out on the west flank of the Sacramento Mountains and slope gently to the east toward the Pecos River.

Following the uplift of the Sacramentos, erosion and stream sediments created a large debris apron on their east slope. Farther east from the debris apron lay the more or less smooth and expansive Chalk Bluff Formation of the Permian Basin. At the onset of climatic change in the Pleistocene, the ancestral Pecos River flowed southeast from the Sangre de Cristo Mountains. Headward erosion of the Chalk Bluff Formation, east of the Sacramento Mountains, enhanced by slump depressions, solution, and subsidence of the carbonate strata, eventually captured the ancestral Pecos River and forced it southward on its present course. A quartzose conglomerate was the first Quaternary deposit laid down in the newly flooded channel, gradually filling in the depressions. This was followed by the much more extensive Blackdom and Orchard Park Terraces (Pleistocene) and finally by the Lakewood Terrace (Holocene).

Some of the Paleozoic rocks can be seen in the Pecos River Valley today. Pennsylvanian mesas still exist in the Sangre de Cristos, and Permian deposits are still exposed above the uppermost river terraces in the southern Pecos River Valley. Along the gently sloping east face of the Sacramento Mountains, eroded limestone from the San Andres Formation (late Permian) is exposed. Remnants of the younger Chalk Bluff Formation (Triassic) can be found farther downslope. Farther eastward lies the Quaternary deposits and the Pecos River. East of the river, the terrain quickly rises again through alluvium, until it reaches the escarpment of the Llano Estacado (Chalk Bluff Formation) of the Great Plains Province. Thus, the oldest rocks found in the Pecos River Valley are Permian in age, but the Quaternary alluvium has much Mississippian and Pennsylvanian sediments from the Sangre de Cristos as its origin. Most of the strata older than Pleistocene are so deeply buried by the Cenozoic stream deposits that drilled water wells have not penetrated them.

The San Andres Limestone and its bottom member, the Glorieta Sandstone, conformably overlie the Abo Formation (sandstone, late Permian). Together, these porous deposits form the artesian water system of the Roswell Artesian Basin.

Four layers of Quaternary deposits fill the floor of the Pecos River Valley in the area east of the 
Sacramento Mountains, extending a short distance upstream along the western tributaries of the Pecos River. The youngest of the four strata, the Lakewood Terrace, is composed of undisturbed silt, sand, limestone gravel, and cobbles, and forms a narrow strip along the Pecos River. These deposits are generally from one to seven meters thick with a maximum of 14 meters thick. The presence of a substantial amount of alkali in the soil renders the Lakewood Terrace suitable only for stock grazing. Stratigraphically below, yet topographically above the Lakewood, lies the Orchard Park Terrace. It forms a broad grassy plain, more or less unbroken, as far south as the Rio Penasco and consists of well stratified clay, silt, sand, gravel, and conglomerate. The level of the Orchard Park Terrace is one to three meters above the level of the Lakewood. Approximately $90 \%$ of the irrigated agricultural activities in the Roswell Artesian Basin are located on the Orchard Park Terrace. Ten to twenty meters higher than the Orchard Park lies the Blackdom Terrace. It also is a broad grassy plain though much divided by erosion. The extra costs to pump San Andres Formation water from below this uppermost terrace preclude agricultural activities on the Blackdom Terrace. Therefore, it also is used only for stock grazing. These terrace deposits are believed to be derived from limestone uplands of the Sacramento Mountains, which implies a small magnetic signature.

The experimental sites chosen in the Pecos River Valley include some areas with groundwater very near the surface and up to 25 meters below the surface. From north to south, they include the shore of Santa Rosa Lake, adjacent to Lea Lake in Bottomless Lakes State Park, two agricultural field sites, and a location $0.4 \mathrm{~km}$ from the Pecos River.

\section{A.5.1 Santa Rosa Lake Site (Site 8)}

The Army Corps of Engineers finished construction of the Santa Rosa dam on the Pecos River in 1981, creating Santa Rosa Lake, now part of Santa Rosa State Park. The NMR site chosen is on the west side of the lake. It has a northeast facing aspect with a juniper-grassland vegetation cover on a five degree slope. Estimated depth to groundwater is one meter.

\section{A.5.2 Lea Lake Site (Site 9)}

Slump depressions and solution of the carbonate strata during the Pleistocene created sinkholes throughout the Permian limestone and gypsum formations of the Pecos Valley region. Sand and gravel of Paleozoic origin transported from the Sangre de Cristo Mountains by the Pecos River filled most of the depressions, but some sinkholes still exist today as deep, natural lakes. Lea Lake is the largest of the lakes in Bottomless Lakes State Park, a group of sinkhole lakes $20 \mathrm{~km}$ southeast of Roswell, New Mexico. The lakes were formed by dissolution and collapse in the underlying Artesia (gypsum) and San Andres (limestone) formations. The survey site is near the northwest shoreline on flat, bare, hard packed ground. Estimated depth to groundwater is approximately 0.7 meter.

\section{A.5.3 Dexter Agricultural Field Site (Site 11)}

The chosen site is adjacent to the "east border" site in the deep percolation study of Roark and Healy (1998). It sits on the Orchard Park River Terrace in a flat, open, agricultural field, approximately $2 \mathrm{~km}$ southwest of the town of Dexter, New Mexico. The soil is of the Reakor series, deep and well-drained, with a light brown loam surface layer, a heavier brown loam - clay loam subsoil, and a pink clay loam substratum, high in calcium carbonate. 


\section{A.5.4 Lake Arthur Agricultural Field Site (Site 12)}

This site is also on the Orchard Park Terrace in a flat, open, crop field, approximately $5 \mathrm{~km}$ northwest of the town of Lake Arthur, New Mexico. Since most of the agricultural area on the Orchard Park Terrace has a Reakor or Reeves (similar to Reakor) series soil, the soil at the Lake Arthur site is similar to that of the Dexter site.

\section{A.5.5 New Mexico State University Experimental Station Site}

The chosen site is on the Lakewood Terrace, on the property of the New Mexico State Experimental Station, approximately $9 \mathrm{~km}$ southeast of the town of Artesia, New Mexico. The site is an abandoned oil well pad about $0.4 \mathrm{~km}$ west of the Pecos River, adjacent to NMSU's Monitoring Well No. 3. It has a fairly heavy silty clay-loam soil and a very dense growth of Salt Cedar. The depth to groundwater at the time of NMR sampling was approximately six meters. 
B 
B THEORETICAL PREPRINT

39 
